\title{
Article \\ Hydrogen Sulfide Improves the Cold Stress Resistance through the CsARF5-CsDREB3 Module in Cucumber
}

\author{
Xiaowei Zhang, Xin Fu, Fengjiao Liu, Yanan Wang, Huangai Bi and Xizhen Ai *
}

check for

updates

Citation: Zhang, X.; Fu, X.; Liu, F.; Wang, Y.; Bi, H.; Ai, X. Hydrogen Sulfide Improves the Cold Stress

Resistance through the

CsARF5-CsDREB3 Module in

Cucumber. Int. J. Mol. Sci. 2021, 22,

13229. https://doi.org/10.3390/

ijms222413229

Academic Editors: Yanjie Xie Francisco J. Corpas and Jisheng Li

Received: 13 November 2021

Accepted: 5 December 2021

Published: 8 December 2021

Publisher's Note: MDPI stays neutral with regard to jurisdictional claims in published maps and institutional affiliations.

Copyright: (c) 2021 by the authors. Licensee MDPI, Basel, Switzerland. This article is an open access article distributed under the terms and conditions of the Creative Commons Attribution (CC BY) license (https:// creativecommons.org/licenses/by/ $4.0 /)$.
State Key Laboratory of Crop Biology, Key Laboratory of Crop Biology and Genetic Improvement of Horticultural Crops in Huanghuai Region, College of Horticulture Science and Engineering, Shandong Agricultural University, Tai'an 271018, China; 2019010077@sdau.edu.cn (X.Z.); 15621321275@163.com (X.F.); lfjsdnd@126.com (F.L.); 18864805562@163.com (Y.W.); bhg163@163.com (H.B.)

* Correspondence: axz@sdau.edu.cn; Tel.: +86-538-8246218

\begin{abstract}
As an important gas signaling molecule, hydrogen sulfide $\left(\mathrm{H}_{2} \mathrm{~S}\right)$ plays a crucial role in regulating cold tolerance. $\mathrm{H}_{2} \mathrm{~S}$ cooperates with phytohormones such as abscisic acid, ethylene, and salicylic acid to regulate the plant stress response. However, the synergistic regulation of $\mathrm{H}_{2} \mathrm{~S}$ and auxin in the plant response to cold stress has not been reported. This study showed that sodium hydrosulfide (NaHS, an $\mathrm{H}_{2} \mathrm{~S}$ donor) treatment enhanced the cold stress tolerance of cucumber seedlings and increased the level of auxin. CSARF5, a cucumber auxin response factor (ARF) gene, was isolated, and its role in regulating $\mathrm{H}_{2} \mathrm{~S}$-mediated cold stress tolerance was described. Transgenic cucumber leaves overexpressing CSARF5 were obtained. Physiological analysis indicated that overexpression of CSARF5 enhanced the cold stress tolerance of cucumber and the regulation of the cold stress response by $\mathrm{Cs} A R F 5$ depends on $\mathrm{H}_{2} \mathrm{~S}$. In addition, molecular assays showed that CsARF5 modulated cold stress response by directly activating the expression of the dehydration-responsive element-binding (DREB)/C-repeat binding factor (CBF) gene CsDREB3, which was identified as a positive regulator of cold stress. Taken together, the above results suggest that CsARF5 plays an important role in $\mathrm{H}_{2} \mathrm{~S}$-mediated cold stress in cucumber. These results shed light on the molecular mechanism by which $\mathrm{H}_{2} \mathrm{~S}$ regulates cold stress response by mediating auxin signaling; this will provide insights for further studies on the molecular mechanism by which $\mathrm{H}_{2} \mathrm{~S}$ regulates cold stress. The aim of this study was to explore the molecular mechanism of $\mathrm{H}_{2} \mathrm{~S}$ regulating cold tolerance of cucumber seedlings and provide a theoretical basis for the further study of cucumber cultivation and environmental adaptability technology in winter.
\end{abstract}

Keywords: ARF; auxin; cold stress; cucumber; DREB; hydrogen sulfide; module; resistance

\section{Introduction}

Cucumber (Cucumis sativus L.) is one of the most important economic crops worldwide. The cultivation and yield of cucumbers in China have ranked among the top in the world for many years. Cucumbers are typical cold-sensitive plants and are generally grown in solar greenhouses in northern China. Because of the extreme low-temperature conditions, cucumbers in greenhouses are prone to cold injury in winter and early spring. Cucumbers with cold injury showed inhibited growth, wilted and died in severe cases. Therefore, it is of great practical significance to study the effects of low-temperature stress on cucumber growth and development and the response mechanism of cucumber to low-temperature stress.

Hydrogen sulfide $\left(\mathrm{H}_{2} \mathrm{~S}\right)$ is a gaseous compound recognized as the third gas signaling molecule discovered after nitric oxide and carbon monoxide [1,2]. $\mathrm{H}_{2} \mathrm{~S}$ has been found to be widespread in mammals and has important cellular protective effects [3,4]. However, $\mathrm{H}_{2} \mathrm{~S}$ is also highly toxic. Low concentrations of $\mathrm{H}_{2} \mathrm{~S}$ can affect the eyes, respiratory system and central nervous system. Inhaling hydrogen sulfide in small concentrations can be fatal [5,6]. In agricultural production, the application of an appropriate concentration of 
$\mathrm{H}_{2} \mathrm{~S}$ can regulate plant growth and development, such as germination, maturation, root development, senescence and defense [7-9]. Numerous investigations have determined that $\mathrm{H}_{2} \mathrm{~S}$ plays a key role in the regulation of abiotic stress responses, including cold tolerance [8,10-12]. Low temperatures trigger $\mathrm{H}_{2} \mathrm{~S}$ biosynthesis $[13,14] . \mathrm{H}_{2} \mathrm{~S}$ is found to alleviate cold stress tolerance in many plant species, although the mechanisms remain elusive [11,13-15]. Several reports show that $\mathrm{H}_{2} \mathrm{~S}$ modulates cold stress response, possibly through mitogen-activated protein kinase (MAPK) signaling $[11,16,17]$. In addition to $\mathrm{H}_{2} \mathrm{~S}$, phytohormones, especially auxin, also play a vital positive regulatory role in cold stress response [18,19].

Auxin is involved in plant growth and development in various aspects, including cell division and elongation, tissue patterning and the response to environmental stimuli $[20,21]$. Since auxin was identified for the first time in the 1930s as indole-3-acetic acid, there has been a major breakthrough in the molecular mechanisms of auxin perception and signal transduction. Many genetic and biochemical approaches have elucidated that the TRANSPORT INHIBTOR RESPONSE1 (TIR1) protein functions as the receptor to perceive auxin signaling based on the reduced auxin response of tir1 mutations [22,23]. Additionally, the SCF ${ }^{\text {TIR1 }}$ ubiquitin-ligase complex is regarded as a central regulator of auxin signaling, and it-mediated proteolysis of auxin/indole acetic acid (Aux/IAA) proteins is responsible for auxin signaling transduction [24,25]. In this signaling pathway, Aux/IAA proteins are direct targets of TIR1. Aux/IAA proteins directly interact with auxin response factors (ARFs) to repress their activities [26]. Upon exposure to auxin, the F-box protein TIR1 recruits the Aux/IAA proteins for degradation, which leads to the release of various auxin response factors, including Small Auxin-up RNAs (SAURs), GH3s and Aux/IAAs, and consequently regulates diverse auxin-mediated plant growth $[27,28]$.

ARFs are vital transcription factors (TFs) that regulate the expression of auxin response genes $[27,29,30]$. To date, 23 and 25 ARF genes have been isolated in Arabidopsis and rice, respectively $[27,31,32]$. Most ARF members consist of a DNA-binding domain (DBD), a variable middle region and a carboxy-terminal dimerization domain (CTD) $[27,33]$. The DBD is classified as a plant-specific B3-type and functions to bind to TGTCTC/GAGACA sites (AuxREs) in vitro [33,34]. The middle region includes two types: activation domaintype (AD) and repression domain-type (RD), which are used as the basis of classification between transcription activators and transcription repressors [30,33]. Additionally, the CTD domain is responsible for protein-protein interactions by dimerizing with Aux/IAA proteins as well as other ARFs [35,36]. Extensive studies have suggested that ARF proteins are involved in distinct developmental processes. In Arabidopsis, numerous ARF genes have been implicated in embryogenesis (ARF5 and ARF17) [37], root growth (ARF7, ARF10, ARF16, and ARF19) [38-41], hypocotyl growth (ARF6, ARF7, ARF8, and ARF19) [42-44], shoot regeneration (ARF4 and ARF5) [45], flower development (ARF2, ARF3, ARF6, and ARF8) [46,47] and senescence (ARF1 and ARF2) [48]. In the case of rice, genetic studies show that the functions of ARFs are different from the functions of Arabidopsis. OsARF1 is involved in root initiation and seed development $[49,50]$. OsARF12 regulates root elongation, iron accumulation and phosphate homeostasis [51,52]. OsARF16 regulates phosphate transport, phosphate starvation and iron deficiency responses [53-55]. OsARF19 controls leaf angles [56]. OsARF11, OsARF12, OsARF16 and OsARF17 are involved in antiviral defences [57,58]. A recent study showed that OsARF6 regulates rice yields [59]. Although a number of ARF members have been functionally characterized in Arabidopsis and rice, as mentioned earlier, little is known about the functions of $A R F$ genes in cucumber.

In this study, the molecular mechanisms by which $\mathrm{H}_{2} \mathrm{~S}$ regulates cold stress response in cucumber were explored. The study suggested that $\mathrm{H}_{2} \mathrm{~S}$ treatment could improve cold resistance and auxin content of cucumber. CsARF5, a transcriptional regulator in auxin signaling, was responsive to cold stress and $\mathrm{H}_{2} \mathrm{~S}$ treatments, and overexpression of CsARF5 improved the cold stress tolerance of cucumber. Further studies indicated that CSARF5 modulated cold stress response by directly activating the expression of the dehydrationresponsive element-binding (DREB)/C-repeat binding factor (CBF) gene CsDREB3. 


\section{Results}

\subsection{Sodium Hydrosulfide (NaHS) Improves Cold Tolerance in Cucumber Seedlings}

A previous study demonstrated that NaHS could improve the cold tolerance of cucumber seedlings in a concentration-dependent manner, and $1.0 \mathrm{mM} \mathrm{NaHS}$ treatment showed a very significant difference compared with the control [60]. Here, Figure 1 shows that $1.0 \mathrm{mM}$ NaHS significantly reduced cold stress injury, accumulation of $\mathrm{H}_{2} \mathrm{O}_{2}$ and superoxide anion $\left(\mathrm{O}_{2} \cdot{ }^{-}\right)$, as well as electrolyte leakage (EL) in cucumber seedlings after exposure to $5{ }^{\circ} \mathrm{C}$ for $48 \mathrm{~h}$. However, $0.15 \mathrm{mM} \mathrm{H}_{2} \mathrm{~S}$ scavenger hypotaurine (HT) increased cold stress injury, $\mathrm{H}_{2} \mathrm{O}_{2}, \mathrm{O}_{2}{ }^{-}$and $\mathrm{EL}$, compared with the deionized water $\left(\mathrm{H}_{2} \mathrm{O}\right.$, as a comparison)-treated seedlings (Figure 1A-F). The mRNA abundance of CsCBF1 and CsCOR in NaHS-treated seedlings also increased by 1.38 -fold and 3.14-fold, respectively, under cold stress, but no obvious differences were observed between $\mathrm{H}_{2} \mathrm{O}$ and HT treatments (Figure $1 \mathrm{G}, \mathrm{H}$ ). Therefore, the results further confirmed that $\mathrm{H}_{2} \mathrm{~S}$ improves cold tolerance in cucumber.


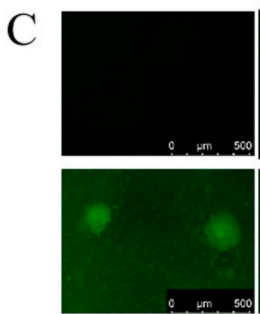

$\mathrm{H}_{2} \mathrm{O}$
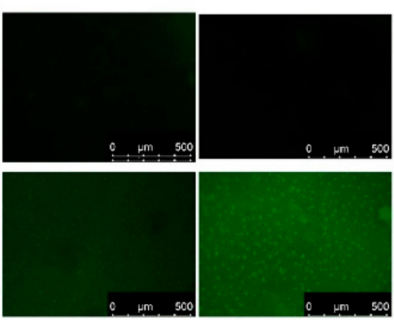

HT

$\mathrm{E}$

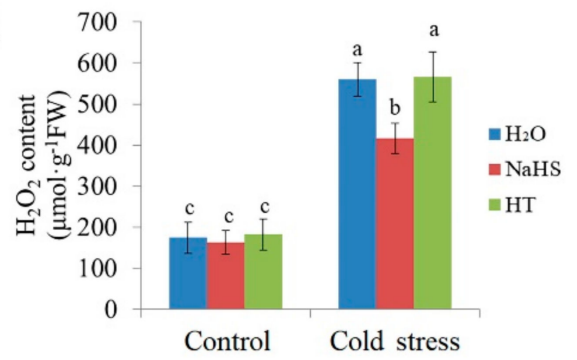

G

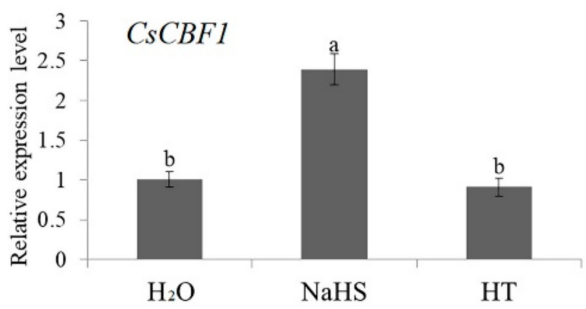

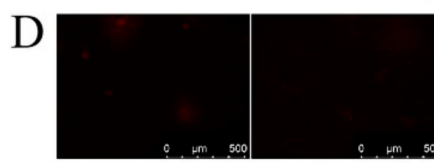

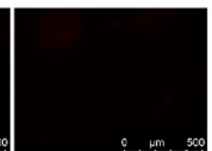

Control

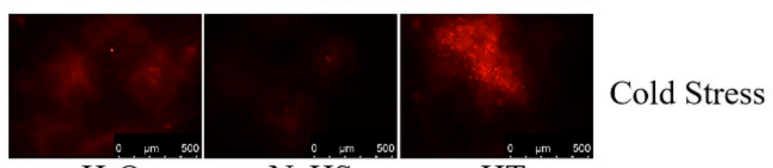

$$
\mathrm{H}_{2} \mathrm{O}
$$

$\mathrm{NaHS}$

HT

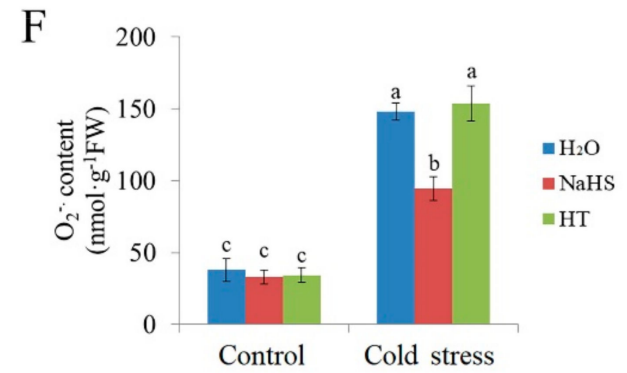

$\mathrm{H}$

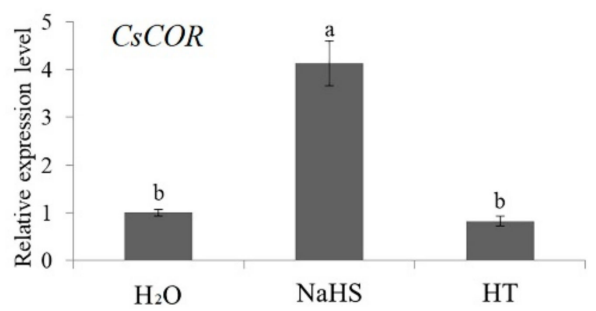

Figure 1. Effects of NaHS and HT on the cold tolerance of cucumber seedlings. Cucumber seedlings were treated with NaHS, HT or deionized water for $24 \mathrm{~h}$ and subsequently were exposed to cold stress. (A) Phenotypic characterization of cucumber seedlings before (control) and after cold stress $\left(5^{\circ} \mathrm{C}\right.$ for $48 \mathrm{~h}$ ). Each treatment contained $5-10$ cucumber seedlings. 
The experiments were repeated three times with similar results. A typical picture is shown here. (B) The EL results of cucumber seedlings before (control) and after cold stress for $48 \mathrm{~h}$. (C,D) Inverted fluorescence microscopy imaging of $\mathrm{H}_{2} \mathrm{O}_{2}$ and $\mathrm{O}_{2} \cdot{ }^{-}$levels in cucumber seedling leaves before (control) and after cold stress treatment for $48 \mathrm{~h}$. (E, $\left.\mathbf{F}\right)$ Detection of $\mathrm{H}_{2} \mathrm{O}_{2}$ and $\mathrm{O}_{2}{ }^{-}$- content of cucumber seedlings before (control) and after cold stress treatment for $48 \mathrm{~h}$. (G,H) Expression of CsCBF1 and CSCOR genes in cucumber seedlings under cold stress treatment for $6 \mathrm{~h}$. qRT-PCR was performed simultaneously with three biological replicates and three technical replicates. The value of the water treatment was used as the reference and was set to 1 . Error bars denote standard deviations. Different letters indicate significant differences $(p<0.05)$ based on Duncan's multiple range tests.

\subsection{NaHS Treatment Affects Auxin Signaling}

To explore the molecular mechanism by which $\mathrm{H}_{2} \mathrm{~S}$ improves cold resistance in cucumber, transcriptome analyses of cucumber seedlings treated with $\mathrm{NaHS}$ and $\mathrm{H}_{2} \mathrm{O}$ were performed. A total of 1952 cucumber genes were analyzed from transcriptome data (Figure 2A). Among these cucumber genes, 118 genes were downregulated, and 54 genes were upregulated (Figure 2A). The upregulated genes were further analyzed (Figure 2B). One of the genes that caught our attention was an auxin response gene (accession number: CsaV3_3G045690, Figure 2B). The NCBI database comparison found that it was the CsARF5 gene.
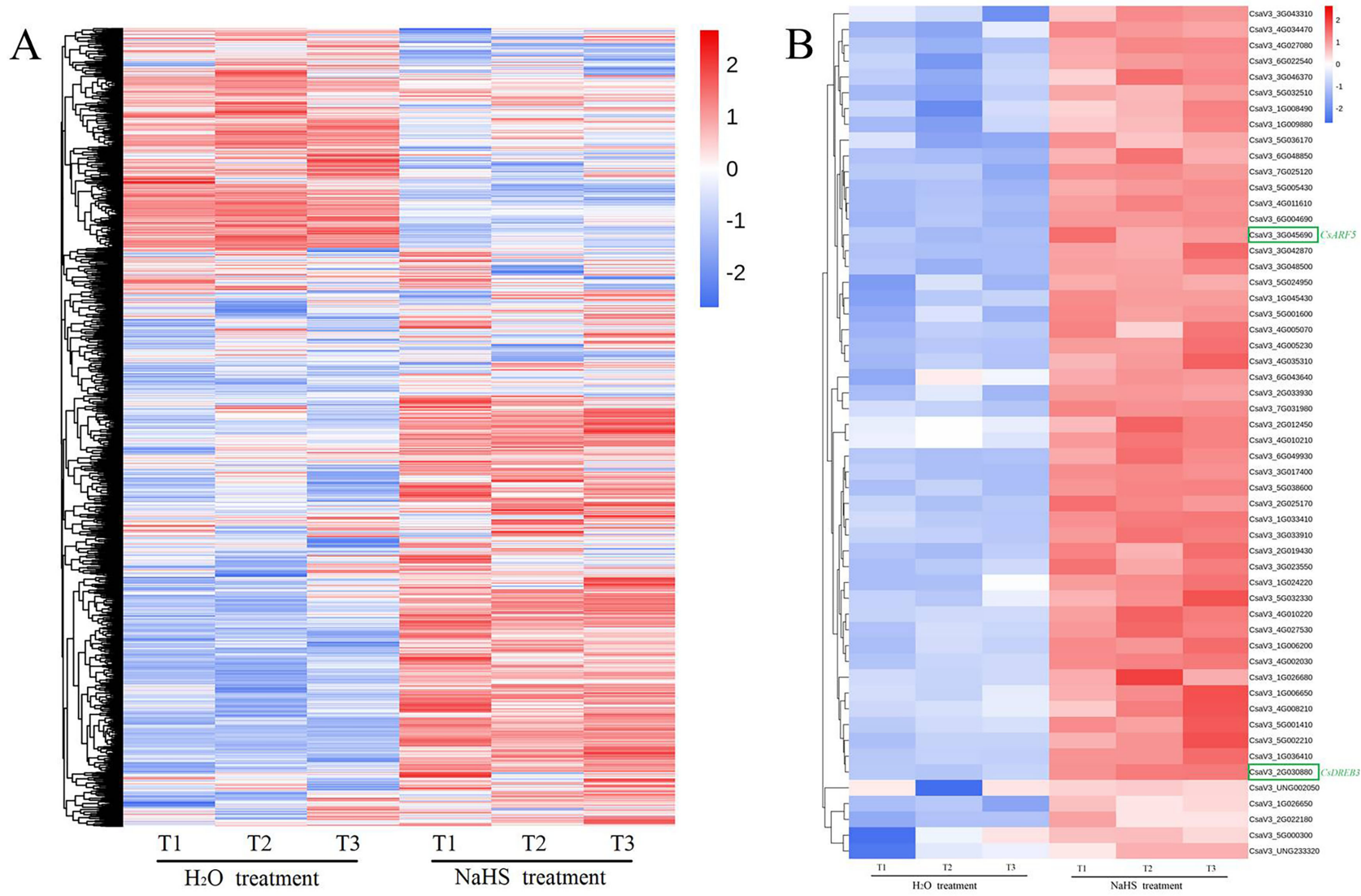

Figure 2. RNA-seq analysis of cucumber seedlings with or without NaHS treatment. (A) Normalized heat map showing the changes in gene expression after NaHS treatment at $5{ }^{\circ} \mathrm{C}$ for $6 \mathrm{~h}$. All experiments were performed in triplicate. (B) Normalized heat map of upregulated gene expression after NaHS treatment at $5{ }^{\circ} \mathrm{C}$ for $6 \mathrm{~h}$. All experiments were performed in triplicate.

To study the effect of NaHS on auxin signaling, the change in auxin content in cucumber seedlings treated with NaHS or HT was estimated. NaHS (1.0 mM) markedly increased endogenous indole-3-acetic acid (IAA) accumulation and flavin monooxygenase (FMO, a key enzyme in auxin synthesis) activity. However, HT treatment revealed lower 
or similar IAA content and FMO activity compared with $\mathrm{H}_{2} \mathrm{O}$ treatment (Figure $3 \mathrm{~A}, \mathrm{~B}$ ). In addition, NaHS treatment also significantly upregulated the mRNA levels of CsARF5 and CSDREB3, while HT-treated seedlings showed no marked differences in the relative mRNA expression of CsARF5 and CsDREB3 relative to the $\mathrm{H}_{2} \mathrm{O}$ treatment (Figure 3C,D). These data indicate that $\mathrm{H}_{2} \mathrm{~S}$ affects auxin signaling in cucumber seedlings under cold stress.
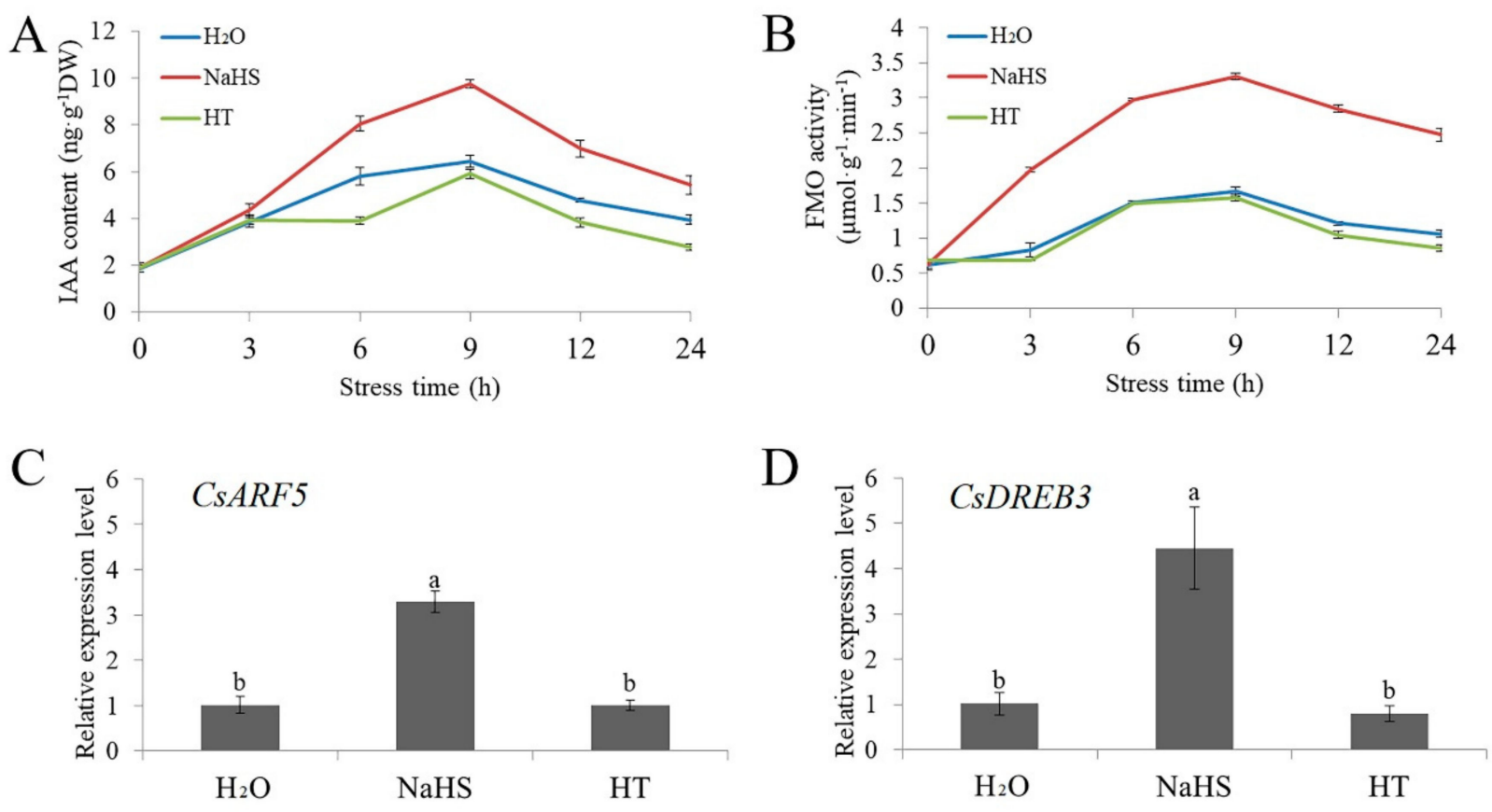

Figure 3. NaHS treatment affects IAA levels in cucumber. (A) The IAA content of cucumber seedlings treated with NaHS or HT under cold stress treatment for $24 \mathrm{~h}$. (B) The FMO activity of cucumber seedlings treated with NaHS or HT under cold stress treatment for $24 \mathrm{~h}$. (C) Expression of the CSARF5 gene in cucumber seedlings treated with NaHS or HT under cold stress treatment for $6 \mathrm{~h}$. (D) Expression of the CSDREB3 gene in cucumber seedlings treated with NaHS or HT under cold stress treatment for $6 \mathrm{~h}$. qRT- PCR was performed simultaneously with three biological replicates and three technical replicates. The value of $0 \mathrm{~h}$ was used as the reference and was set to 1 . Error bars denote standard deviations. Different letters indicate significant differences $(p<0.05)$ based on Duncan's multiple range tests.

\subsection{IAA Treatment Improves Cold Resistance of Cucumber Seedlings}

A previous study showed that $75 \mu \mathrm{M}$ IAA enhances the cold tolerance of cucumber seedlings [60]. Here, Figure 4 shows that $75 \mu \mathrm{M}$ IAA significantly reduced the EL, and accumulation of $\mathrm{H}_{2} \mathrm{O}_{2}$ and $\mathrm{O}_{2} \cdot{ }^{-}$caused by cold stress, while $50 \mu \mathrm{M}$ 1-naphthylphthalamic acid (NPA, a polar transport inhibitor) treatment showed no remarkable difference relative to $\mathrm{H}_{2} \mathrm{O}$ treatment under cold stress (Figure $4 \mathrm{~A}-\mathrm{F}$ ). As an auxin response factor, the relative mRNA expression of CSARF5 was upregulated in IAA-treated seedlings under cold stress. However, no remarkable difference was found in the mRNA expression of CsARF5 between the NPA and $\mathrm{H}_{2} \mathrm{O}$ treatments (Figure 4G). The mRNA expression levels of CsCBF1 and CsCOR were significantly upregulated in IAA-treated seedlings but downregulated or not influenced in HT-treated seedlings compared with $\mathrm{H}_{2} \mathrm{O}$-treated seedlings when exposed to cold stress (Figure $4 \mathrm{H}, \mathrm{I}$ ). The latest results are in keeping with the earlier findings [60], so the results further confirm that IAA enhances cold tolerance in cucumber.

\subsection{CsARF5 Positively Regulates Cold Stress Tolerance of Cucumber}

qRT-PCR results showed that cold stress increased the mRNA abundance of the CSARF5 gene, and the expression reached a peak after seedlings were exposed to cold for $3 \mathrm{~h}$ and then decreased gradually (Figure 5A). Compared with the control and HT treatments, NaHS treatment further increased the expression of CSARF5 (Figure 5B). These results demonstrate that CsARF5 is responsive to cold stress and $\mathrm{H}_{2} \mathrm{~S}$ treatment. 


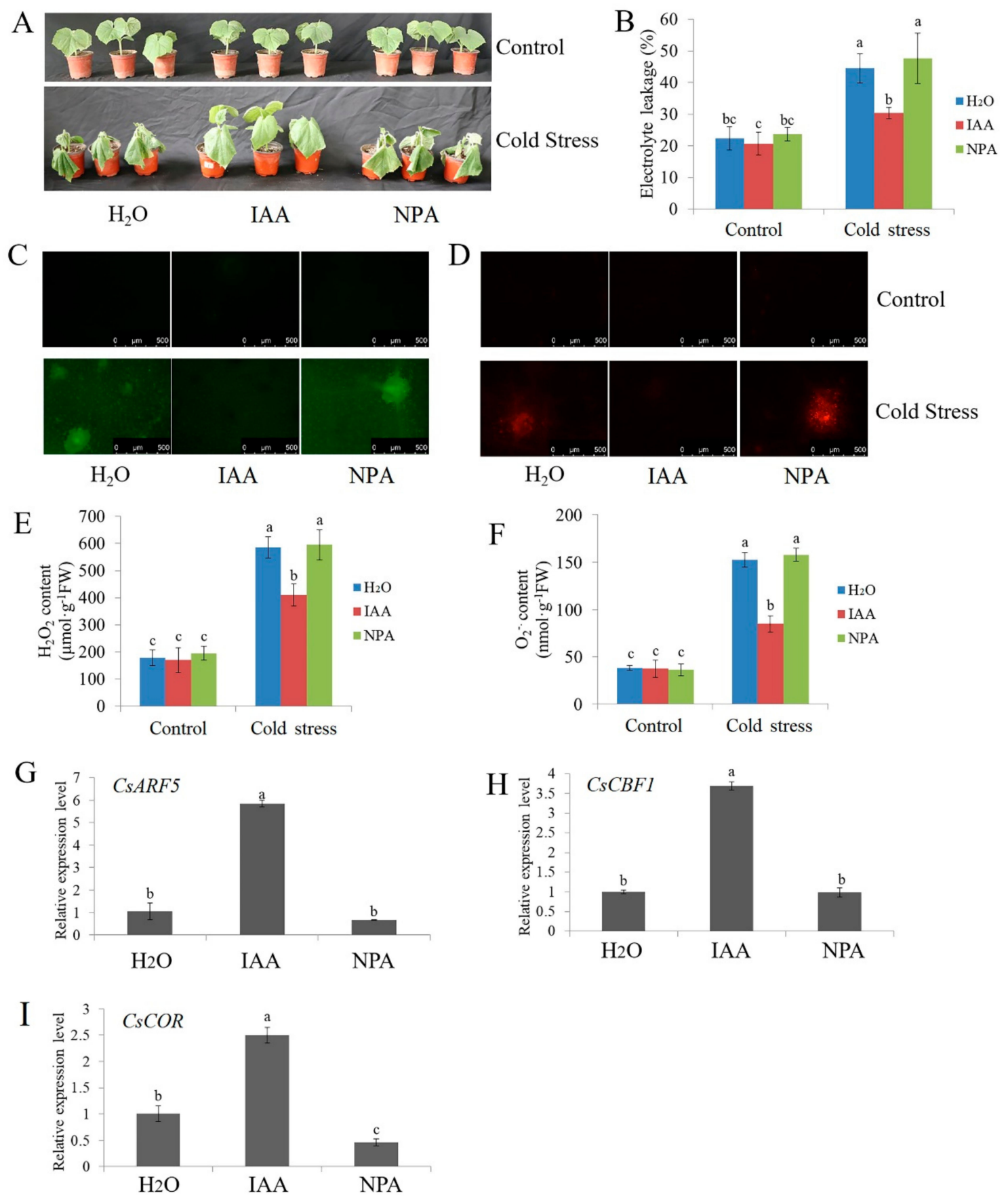

Figure 4. Effects of IAA and NPA on the cold resistance of cucumber seedlings. Cucumber seedlings were treated with IAA, NPA or deionized water for $24 \mathrm{~h}$ and subsequently were exposed to cold stress. (A) Phenotypic characterization of cucumber seedlings before (control) and after cold stress $\left(5^{\circ} \mathrm{C}\right.$ for $48 \mathrm{~h}$ ). Each treatment contained $5-10$ cucumber seedlings. The experiments were repeated three times with similar results. A typical picture is shown here. (B) The EL results of cucumber seedlings before (control) and after cold stress treatment for $48 \mathrm{~h}$. (C,D) Inverted fluorescence microscopy imaging of $\mathrm{H}_{2} \mathrm{O}_{2}$ and $\mathrm{O}_{2} \cdot-$ levels in cucumber seedling leaves before (control) and after cold stress treatment for $48 \mathrm{~h}$. (E,F) Detection of $\mathrm{H}_{2} \mathrm{O}_{2}$ and $\mathrm{O}_{2}{ }^{-}$accumulation of cucumber seedlings before (control) and after cold stress treatment for $48 \mathrm{~h}$. (G-I) Expression of CsARF5, CsCBF1 and CsCOR genes in cucumber seedlings under cold stress for $6 \mathrm{~h}$. qRT-PCR was performed simultaneously with three biological replicates and three technical replicates. The value of the water treatment was used as the reference and was set to 1 . Error bars denote standard deviations. Different letters indicate significant differences $(p<0.05)$ based on Duncan's multiple range tests. 
A

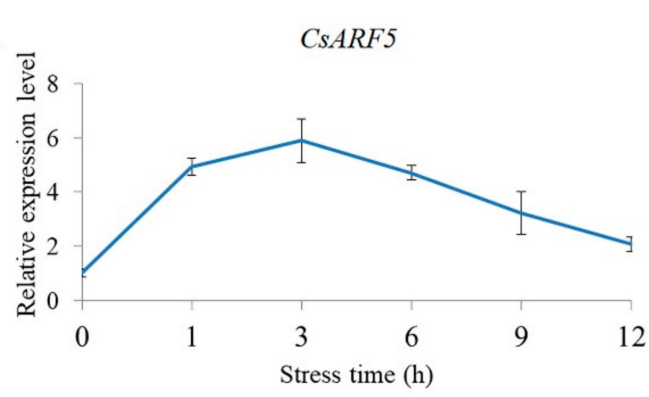

C

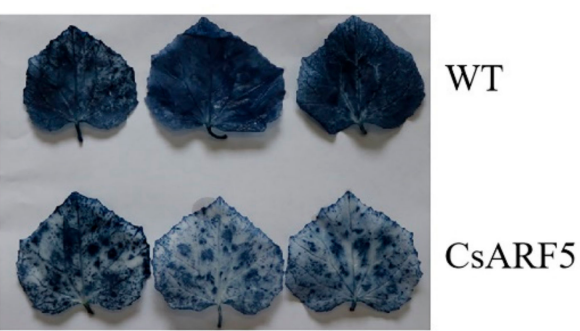

E

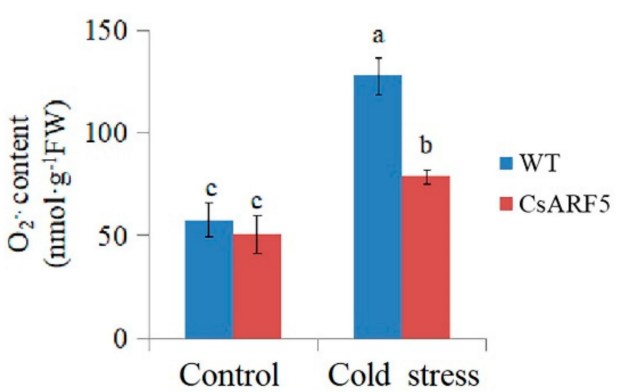

$\mathrm{G}$

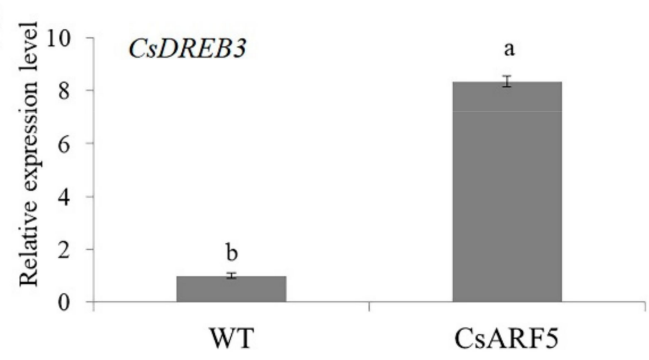

I

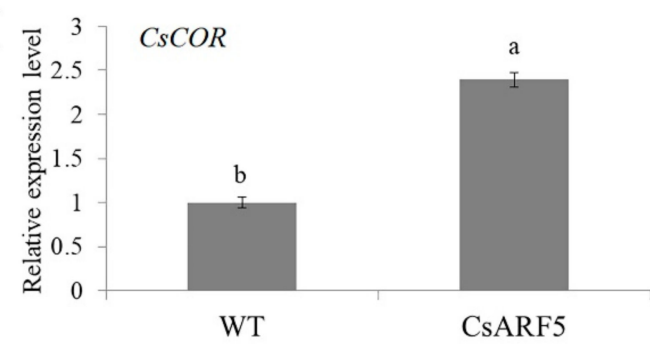

B

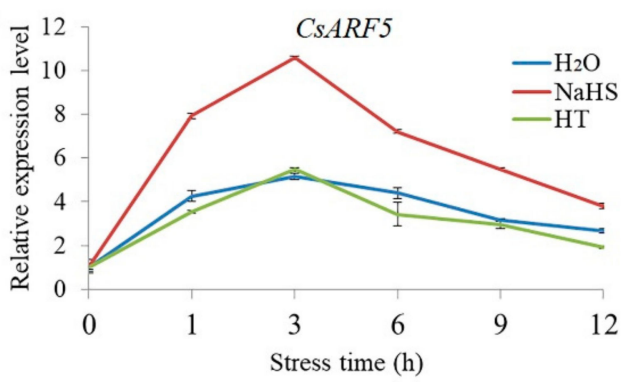

D

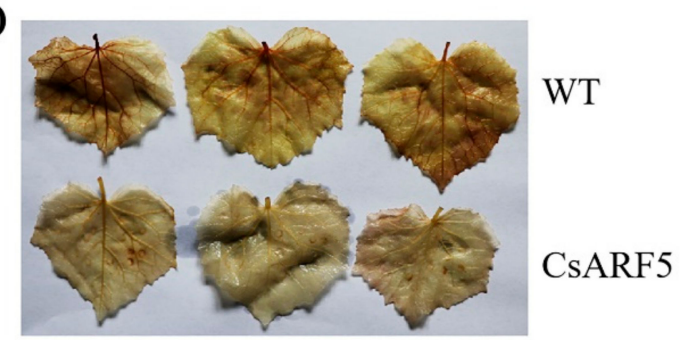

F

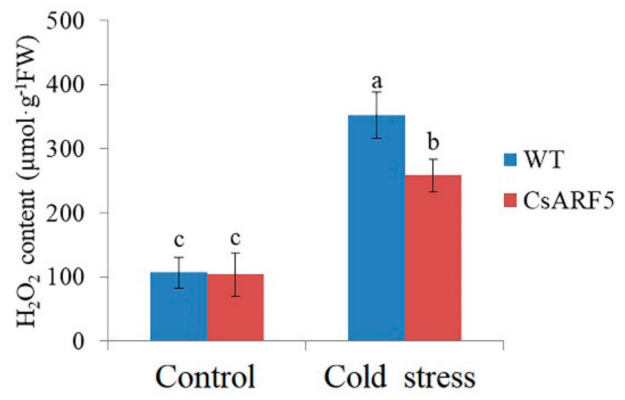

$\mathrm{H}$

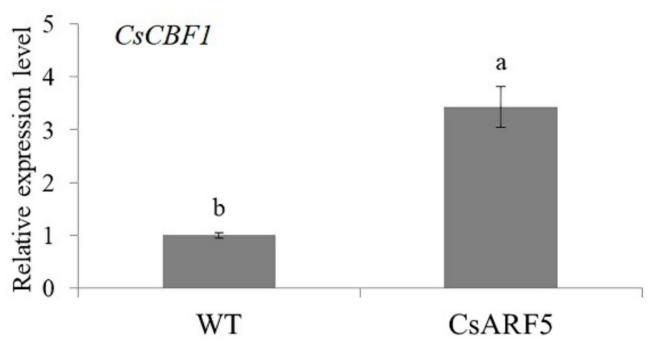

Figure 5. Overexpression of CSARF5 improves cold tolerance of cucumber. (A) Expression of the CSARF5 gene in cucumber seedlings under cold stress treatment for $12 \mathrm{~h}$. (B) Expression of the CSARF5 gene in cucumber seedlings treated with NaHS or HT under cold stress treatment for $12 \mathrm{~h}$. (C,D) NBT and DAB staining of empty vector control (WT) and CsARF5 transient transgenic cucumber leaves treated with cold stress for $12 \mathrm{~h}$. Each genotype contained 5-10 cucumber leaves. The experiments were repeated three times with similar results. A typical picture is shown here. $(\mathbf{E}, \mathbf{F})$ Detection of $\mathrm{O}_{2}{ }^{-}$and $\mathrm{H}_{2} \mathrm{O}_{2}$ contents of transgenic cucumber leaves before (control) and after cold stress treatment for $12 \mathrm{~h}$. (G-I) Expression of CsDREB3, CsCBF1 and CsCOR genes in transgenic cucumber leaves under cold stress for $3 \mathrm{~h}$. qRT-PCR was performed simultaneously with three biological replicates and three technical replicates. The value of WT was used as the reference and was set to 1 . Error bars denote standard deviations. Different letters indicate significant differences $(p<0.05)$ based on Duncan's multiple range tests. 
To further explore the role of CSARF5 in response to cold stress in cucumber, we obtained CSARF5 transgenic cucumber leaves through Agrobacterium-mediated transient genetic transformation (Supplemental Figure S1A). Then, the accumulation of reactive oxygen species (ROS) in transgenic leaves after exposure to cold stress for $12 \mathrm{~h}$ were observed, using nitroblue tetrazolium (NBT) and 3, 3-diaminobenzidine (DAB) staining. The results showed that the accumulation of ROS in cucumber leaves overexpressing CSARF5 (CsARF5) was lower than that of the empty vector control (WT) under cold stress (Figure 5C,D). In addition, the contents of $\mathrm{O}_{2}{ }^{--}$and $\mathrm{H}_{2} \mathrm{O}_{2}$ were measured with biochemical analysis, and the results were in agreement with the NBT and DAB staining images (Figure 5E,F). qRT-PCR results revealed that CsARF5 overexpression upregulated the mRNA level of cold stress-responsive genes CsDREB3, CsCBF1 and CsCOR (Figure 5G-I). These data suggest that CSARF5 is a positive regulator of cold stress response.

\subsection{HT Treatment Affects CsARF5-Mediated Cold Stress Tolerance}

Considering that $\mathrm{H}_{2} \mathrm{~S}$ induces the expression of CsARF5, and that CsARF5 positively regulates cold stress resistance, the role of CsARF5 in $\mathrm{H}_{2} \mathrm{~S}$-mediated cold stress was further explored. The $\mathrm{H}_{2} \mathrm{~S}$ scavenger $\mathrm{HT}$ was applied to CsARF5-overexpressing cucumber leaves to observe ROS accumulation. The NBT and DAB staining results showed that the application of HT alleviated the CsARF5-decreased ROS accumulation in detached cucumber leaves (Figure $6 \mathrm{~A}, \mathrm{~B}$ ). The biochemical analysis for $\mathrm{O}_{2} \cdot{ }^{-}$and $\mathrm{H}_{2} \mathrm{O}_{2}$ was consistent with the NBT and DAB staining results (Figure $6 \mathrm{C}, \mathrm{D}$ ). qRT-PCR results showed that the application of HT inhibited the promotion of CsDREB3, CsCBF1 and CsCOR mRNA expression levels caused by CsARF5 (Figure 6E-G). These results suggest that the regulation of the cold stress response by $\mathrm{Cs} A R F 5$ depends on $\mathrm{H}_{2} \mathrm{~S}$.

\subsection{Overexpression of CsDREB3 Enhances Cold Stress Tolerance of Cucumber}

DREB/CBF TFs play essential roles in the regulation of the plant cold stress response [61,62]. CsDREB3 was induced by NaHS (Figure 2B), which prompted us to explore whether CsDREB3 was involved in the cold stress response in cucumber. As shown in Figure 7A, cold stress induced the expression of the CsDREB3 gene, and the expression reached a peak at $3 \mathrm{~h}$, and then decreased gradually. Compared with the control and HT treatments, NaHS treatment further increased the expression of CsDREB3 (Figure 7B).

To investigate the role of CsDREB3 in response to cold stress in cucumber, CsDREB3 transient transgenic cucumber leaves were obtained (Supplemental Figure S1B). NBT and DAB staining results showed that overexpression of $C s D R E B 3$ decreased ROS accumulation after cold stress treatment (Figure $7 \mathrm{C}, \mathrm{D}$ ). In addition, $\mathrm{O}_{2}{ }^{-}{ }^{-}$and $\mathrm{H}_{2} \mathrm{O}_{2}$ detection results also revealed that the accumulation of $\mathrm{O}_{2}{ }^{-}$and $\mathrm{H}_{2} \mathrm{O}_{2}$ was significantly lower in leaves of overexpressing CsDREB3 than in WT leaves (Figure 7E,F). qRT-PCR results suggested that overexpression of CsDREB3 increased the expression of CsCBF1 and CsCOR (Figure 7G,H). These data demonstrate that CsDREB3 positively regulates the cold tolerance of cucumber.

\subsection{CsARF5 Directly Activates the Expression of CsDREB3}

CsARF5 acts as an auxin response factor and can bind to the AuxRE motif in the promoters of target genes [27]. Considering the similar expression patterns of CSARF5 and CsDREB3 in cold stress and $\mathrm{H}_{2} \mathrm{~S}$ treatment, as well as the key role of DREB/CBF TFs in the regulation of the cold stress response, we hypothesized that CsARF5 might be involved in the cold stress response by mediating the expression of CsDREB3. Then, the sequence of the CsDREB3 gene promoter region was analyzed, and a putative AuxRE motif was found (Figure 8A). Fortunately, the direct binding between the CsARF5 protein and the promoter of CsDREB3 was detected by electromobility shift assay (EMSA) (Figure 8B). To test how CsARF5 regulated the expression of CsDREB3, dual luciferase assays in tobacco leaves were performed. The CsARF5 effector construct was expressed under the $35 \mathrm{~S}$ promoter, and the promoter of CsDREB3 was fused to the Luc gene as a reporter (Figure $8 \mathrm{C}$ ). The results showed that co-expression of 35Spro:CsARF5 with CsDREB3pro: Luc led to an obvious 
increase in luminescence intensity (Figure $8 \mathrm{D}, \mathrm{E}$ ), while the binding site was mutated, and the activation was abolished (Figure 8D,E). These results suggest that CsARF5 transactivates the expression of CsDREB3 in cucumber.
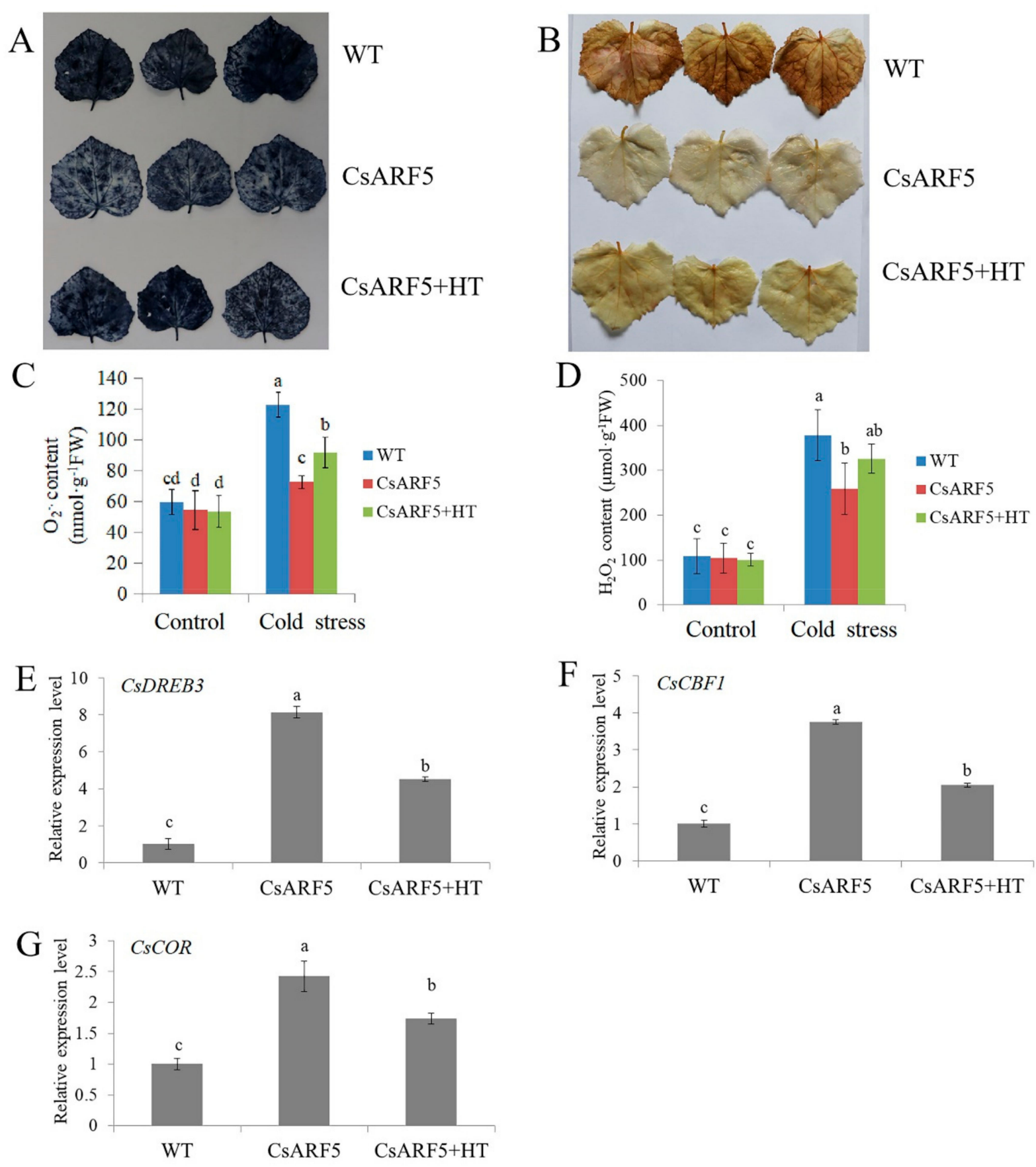

Figure 6. Effect of HT on the cold resistance of CsARF5 transgenic cucumber. (A,B) NBT and DAB staining of empty vector control (WT), CSARF5 transient transgenic cucumber leaves (CsARF5) and CsARF5 sprayed with HT (CsARF5+HT) treated with cold stress for $12 \mathrm{~h}$. Each genotype contained 5-10 cucumber leaves. The experiments were repeated three times with similar results. A typical picture is shown here. (C,D) Detection of $\mathrm{O}_{2}{ }^{--}$and $\mathrm{H}_{2} \mathrm{O}_{2}$ contents of transgenic cucumber leaves before (control) and after cold stress or HT treatment for $12 \mathrm{~h}$. (E-G) Expression of CsDREB3, CsCBF1 and CsCOR genes in transgenic cucumber leaves under cold stress for $3 \mathrm{~h}$. qRT- PCR was performed simultaneously with three biological replicates and three technical replicates. The value of WT was used as the reference and was set to 1. Error bars denote standard deviations. Different letters indicate significant differences $(p<0.05)$ based on Duncan's multiple range tests. 

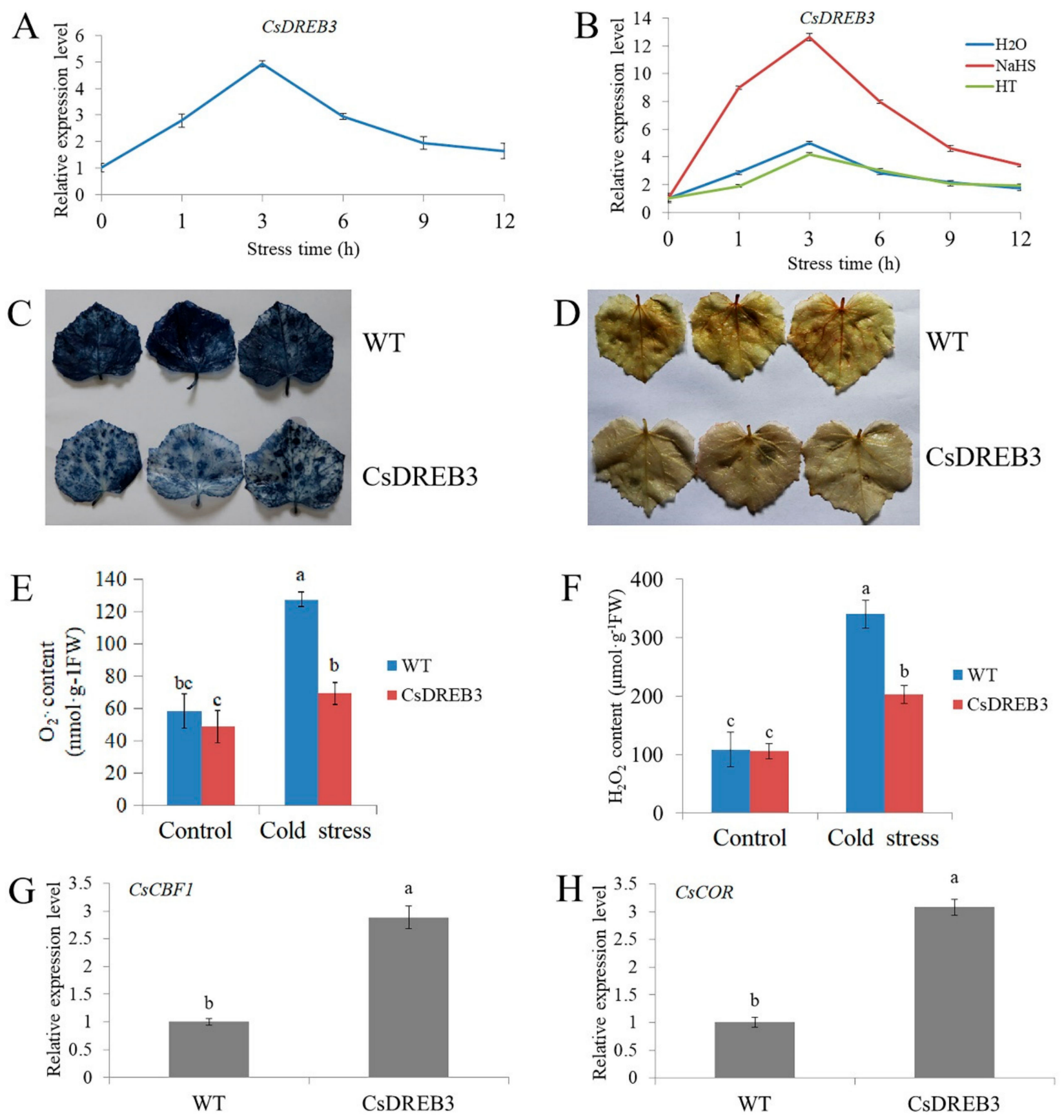

Figure 7. Overexpression of CSDREB3 improves the cold tolerance of cucumber. (A) Expression of the CsDREB3 gene in cucumber seedlings under cold stress treatment for $12 \mathrm{~h}$. (B) Expression of the CsDREB3 gene in cucumber seedlings treated with NaHS or HT under cold stress treatment for $12 \mathrm{~h}$. (C,D) NBT and DAB staining of empty vector control (WT) and CSDREB3 transient transgenic cucumber leaves treated with cold stress for $12 \mathrm{~h}$. Each genotype contained 5-10 cucumber leaves. The experiments were repeated three times with similar results. A typical picture is shown here. (E,F) Detection of $\mathrm{O}_{2} \cdot{ }^{-}$and $\mathrm{H}_{2} \mathrm{O}_{2}$ contents of transgenic cucumber leaves before (control) and after cold stress treatment for $12 \mathrm{~h} .(\mathbf{G}, \mathbf{H})$ Expression of CsCBF1 and CsCOR genes in transgenic cucumber leaves under cold stress for $3 \mathrm{~h}$. qRT-PCR was performed simultaneously with three biological replicates and three technical replicates. The value of WT was used as the reference and was set to 1 . Error bars denote standard deviations. Different letters indicate significant differences $(p<0.05)$ based on Duncan's multiple range tests. 


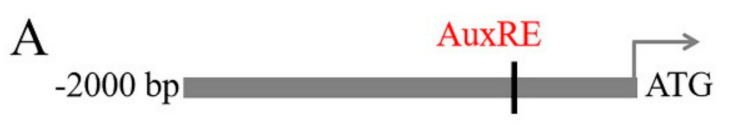

CsDREB3 Promoter

AuxRE

CsDREB3

ATCGGGGTAAGAGACATTAAGAAACA

CsDREB3-mut

ATCGGGGTAAGGGAAATTAAGAAACA

C Reporter plasmid



Effector plasmid
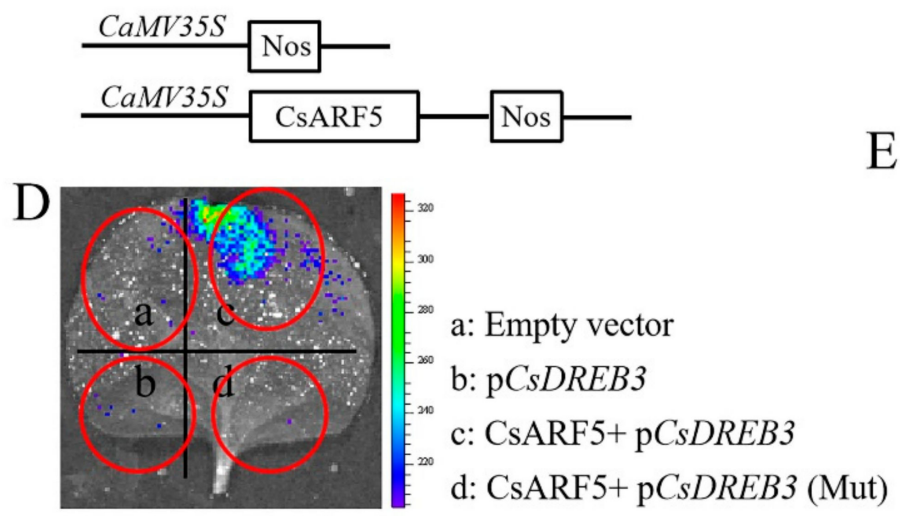
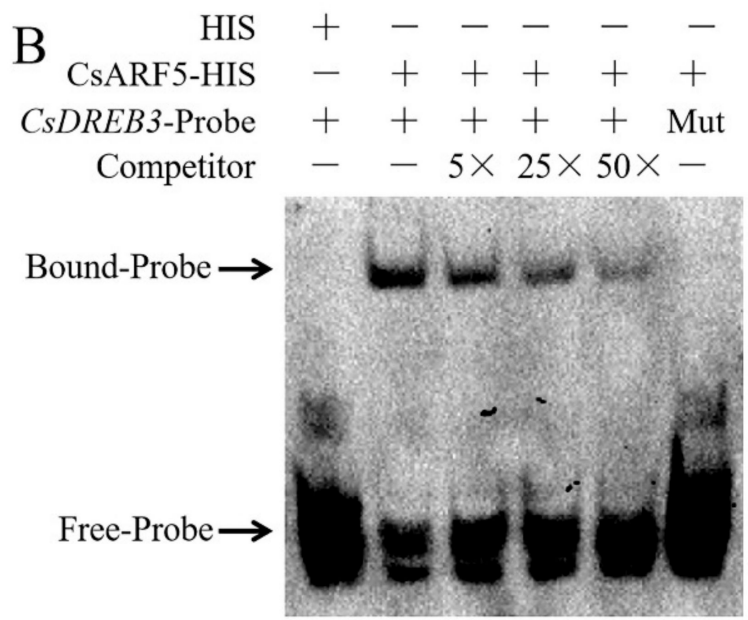

Figure 8. CsARF5 directly modulates the expression of CSDREB3. (A) Schematic diagram showing the CsDREB3 promoter probe used for EMSAs. Mutated probe (CsDREB3-mut) in which the $5^{\prime}$-GAGACA-3' motif was replaced by $5^{\prime}$-GGGAAA-3'. (B) EMSAs show that CsARF5 binds to the MdDREB3 promoter. The experiments were repeated three times with similar results. A typical picture is shown here. (C) Schematic representation of the LUC reporter vector containing the CsDREB3 promoter and the effector vectors expressing CSARF5 under the control of the 35S promoter. (D) Dual luciferase tests in tobacco leaves showing that CsARF5 activates CsDREB3 transcription. Mutated promoter sequence (pCsDREB3-Mut) in which the $5^{\prime}$-GAGACA-3' motif was replaced by $5^{\prime}$-GGGAAA- $3^{\prime}$. The experiments were repeated three times with similar results. A typical picture is shown here. (E) LUC/REN activity detection to verify that CsARF5 activates the transcription of CSDREB3. Empty vector was used as the reference and set to 1. Error bars denote standard deviations. Different letters indicate significant differences $(p<0.05)$ based on Duncan's multiple range tests. All experiments were performed three times with similar results, and representative data from one repetition are shown.

\section{Discussion}

$\mathrm{H}_{2} \mathrm{~S}$, as a gaseous signaling molecule, plays a crucial role in plant relevance to various stress conditions, such as low temperature, salt, drought and heavy metals [12,63]. A report showed that the exogenous application of the $\mathrm{H}_{2} \mathrm{~S}$ donor NaHS could effectively improve plant growth and stress response [64]. In this study, NaHS treatment reduced the accumulation of ROS and activated the expression of cold stress-responsive genes, thus improving the cold-tolerance of cucumber seedlings (Figure 1), suggesting that the response of $\mathrm{H}_{2} \mathrm{~S}$ to cold stress is consistent in different species [64]. Previous reports indicate that $\mathrm{H}_{2} \mathrm{~S}$ and phytohormones have synergistic effects on the $\mathrm{H}_{2} \mathrm{~S}$-mediated plant 
stress response [65]. For example, $\mathrm{H}_{2} \mathrm{~S}$ interacts with abscisic acid (ABA) and ethylene and is involved in the plant response to drought stress and in the regulation of stomatal closure $[66,67]$. Salicylic acid (SA) may play a key role in $\mathrm{H}_{2} \mathrm{~S}$-alleviated heavy metal stress and low-temperature stress [68,69]. Jasmonic acid (JA) stimulation increases the $\mathrm{H}_{2} \mathrm{~S}$ level of protective cells and induces stomatal closure in Vicia faba [70]. Here, the study found that NaHS treatment promoted IAA synthesis and upregulated the expression of auxin-responsive genes (Figures 2 and 3 ), indicating that $\mathrm{H}_{2} \mathrm{~S}$ may crosstalk with auxin to regulate the cold stress response of cucumber.

Several plant hormones, such as JA, SA and ethylene, have been shown to play key roles in the plant's response to cold stress [66-69,71-73]. However, the role of auxin under cold stress is limited. Auxin is a crucial phytohormone that is involved in a variety of plant physiological and developmental processes, including the regulation of the cold stress response $[74,75]$. Previous investigations have determined that cold stress promotes auxin biosynthesis or changes the auxin gradient distribution, thus affecting the root gravity response in Arabidopsis, rice and poplar [18,19,76,77]. A recent study showed that the auxin signaling repressor IAA14 plays an important role in integrating microRNAs with auxin and cold reactions in Arabidopsis [78]. However, studies on the effects of auxin on plant cold stress response are not sufficient. This study showed that the application of auxin improved cold resistance, whereas the application of the polar transport inhibitor NPA slightly reduced the cold resistance of cucumber seedlings (Figure 4), demonstrating that auxin is a positive regulator of the cold stress response.

As a master regulator of auxin signaling, ARF TFs have been functionally characterized in Arabidopsis, rice and populus trichocarpa [27,31,32,79]. An increasing number of studies have indicated that ARFs regulate multiple plant developmental processes such as root growth [40,41], flower development [46,47], senescence [48] and stress response [19,80]. Among these processes, the auxin-regulated cold stress response has become a major focus of biotechnology in cucumber, with the task of identifying the cold resistance genes and improving the yield of cucumber. In this study, an ARF TF, CsARF5, was isolated from cucumber, and its expression was induced by NaHS and cold stress treatments, suggesting that CsARF5 may be involved in $\mathrm{H}_{2} \mathrm{~S}$-mediated cold tolerance (Figure $5 \mathrm{~A}, \mathrm{~B}$ ).

To investigate the functions of CsARF5, transgenic cucumber leaves overexpressing CSARF5 were generated (Supplemental Figure S1A). As hypothesized, the physiology and genetic analysis indicated that the overexpression of CSARF5 decreased the accumulation of ROS and increased the expression level of cold stress-responsive genes, thus improving the cold stress resistance of cucumber (Figure 5). These results suggest that CsARF5 positively regulates the cold stress tolerance of cucumber. Meanwhile, the $\mathrm{H}_{2} \mathrm{~S}$ scavenger HT was applied to CsARF5-overexpressing cucumber leaves to study the role of CSARF5 in $\mathrm{H}_{2} \mathrm{~S}$-mediated cold stress. The results showed that HT inhibited the cold stress resistance increased by CSARF5 (Figure 6), indicating that the regulation of the cold stress response by CsARF5 depends on $\mathrm{H}_{2} \mathrm{~S}$.

DREB/CBF proteins play important roles in the regulation of the plant cold stress response [64,65]. In Arabidopsis, DREB1A, DREB2C, CBF1, CBF2 and CBF3 are involved in the cold stress response [62,81-83]. In rice, OsDREB1A, OsDREB1B, OsDREB1C, OsDREB1F, OsDREB2B and OsDREBL are responsive to cold stress treatment [84-87]. Here, cucumber $D R E B$ genes, namely CsDREB3, were induced by NaHS and cold stress treatments, and overexpression of CSDREB3 significantly enhanced the cold stress tolerance of cucumber (Figure 7, Supplemental Figure S1B), revealing that CsDREB3 is a positive regulator of cold stress.

ARF5 is known to function as a transcriptional activator [27]. The remarkable expression of CsDREB3 in CsARF5 transgenic leaves prompted us to consider whether CsARF5 can directly regulate CsDREB3 expression (Figure 5G). The putative AuxRE elements that were recognized by CsARF5 were searched in the promoter region of CsDREB3. Fortunately, one AuxRE site was found, and the results of EMSAs and dual luciferase assays provided 
evidence to show that CsARF5 could bind to the promoter of CsDREB3 and activate its expression (Figure 8).

Based on previous studies in model plant species and our results in this study, a working model of CsARF5 regulating the $\mathrm{H}_{2} \mathrm{~S}$-mediated cold stress response was proposed (Figure 9). CsIAA proteins interact with CsARF5 and interfere with the transcriptional regulation of CsDREB3 by CsARF5. When $\mathrm{H}_{2} \mathrm{~S}$ signaling was detected, auxin levels in cucumber were increased, and CsARF5 was freed from the CsIAA protein complex. Then, CsARF5 specifically activated the expression of CSDREB3 to improve the cold tolerance of cucumber. Our study elucidates the molecular mechanism by which $\mathrm{H}_{2} \mathrm{~S}$ regulates the cold stress response in cucumber by mediating auxin signaling, which will provide insights for further studies on the molecular mechanisms by which $\mathrm{H}_{2} \mathrm{~S}$ regulates cold stress. A better understanding of the function and signal transduction of CsARF5 in cucumber is helpful to regulate the resistance of cucumber to low-temperature stress to obtain high-quality fruit.


Figure 9. A regulatory model elucidates that $\mathrm{H}_{2} \mathrm{~S}$ mediates the cold stress response in cucumber through auxin signaling. In the absence of $\mathrm{H}_{2} \mathrm{~S}$, IAA repressor proteins inhibit the expression of CsARF5, which in turn inhibits the cold stress response mediated by the CsARF5-CsDREB3 module. In the presence of $\mathrm{H}_{2} \mathrm{~S}$, IAA repressor proteins release CsARF5, which promotes the cold stress response by activating CSDREB3 expression.

\section{Materials and Methods}

\subsection{Plant Material and Growth Conditions}

'Jinyou 35' cucumber seedlings were used for cold stress treatment and genetic transformation. After soaking and germinating, the cucumber seeds were sown in nutrition bowls and transferred to a climate chamber with a PFD of $600 \mu \mathrm{mol} \mathrm{m}{ }^{-2} \cdot \mathrm{s}^{-1}$, a $25^{\circ} \mathrm{C} / 16^{\circ} \mathrm{C}$ thermo-period, an 11-h photoperiod and $80 \%$ relative humidity.

\subsection{Vector Construction and Transient Transformation}

To generate CsARF5 and CsDREB3 overexpression vectors, full-length CSARF5 and CsDREB3 were inserted into the pCAMBIA1300 plasmid. 
For the transient transformation of detached cucumber leaves, cucumber leaves with the same growth conditions were taken, and Agrobacterium tumefaciens LBA4404 (Weidi, Shanghai, China) with overexpression vector was injected into cucumber leaves through a medical syringe.

\subsection{Cold Stress Treatments}

To evaluate the effect of $\mathrm{H}_{2} \mathrm{~S}$ and IAA on the cold resistance of cucumber, cucumber seedlings with two leaves were foliar sprayed with $1.0 \mathrm{mM} \mathrm{NaHS}$ (an $\mathrm{H}_{2} \mathrm{~S}$ donor; Shanghai Macklin Biochemical Co., Ltd., Shanghai, China), $0.15 \mathrm{mM} \mathrm{HT}$ (a specific scavenger of $\mathrm{H}_{2} \mathrm{~S}$; Sigma-Aldrich, Shanghai, China) and deionized water $\left(\mathrm{H}_{2} \mathrm{O}\right)$, respectively, or pretreated with $75 \mu \mathrm{M}$ IAA (Solarbio, Beijing, China), $50 \mu \mathrm{M}$ NPA (a polar transport inhibitor of IAA; Shanghai Aladdin Biochemical Technology Co., Ltd., Shanghai, China) or deionized water $\left(\mathrm{H}_{2} \mathrm{O}\right)$, respectively. Twenty-four hours later, half of the treatments were exposed to low temperatures $\left(5^{\circ} \mathrm{C}\right)$, and the other half of the seedlings were placed at normal temperatures as the control. The EL and accumulation of ROS were determined at $48 \mathrm{~h}$ after exposure of seedlings to $5^{\circ} \mathrm{C}$. Leaf samples of seedlings pretreated with $\mathrm{H}_{2} \mathrm{O}$ and $1.0 \mathrm{mM}$ NaHS were collected from 3 plants $(n=3)$ for transcriptome analysis after $6 \mathrm{~h}$ of cold stress.

To compare the difference in cold tolerance between WT and transgenic cucumber leaves, the pCAMBIA1300 empty vectors and overexpressed CsARF5 and CsDREB3 vectors were injected into the first leaf, which was just flat of cucumber. Twelve hours later, WT leaves, CsDREB3 overexpressing leaves, and some CsARF5 overexpressing leaves were exposed to $5{ }^{\circ} \mathrm{C}$. Other CsARF5 overexpressing leaves were treated with HT and then exposed to $5{ }^{\circ} \mathrm{C}$ after the water droplets on the leaves were absorbed and dried. The gene expression of $C s D R E B 3, C s C B F 1$ and $C s C O R$ in transgenic cucumber leaves was measured at $3 \mathrm{~h}$ after exposure to cold stress. NBT staining, DAB staining and ROS content were detected after cold treatment for $12 \mathrm{~h}$.

\section{4. $q R T-P C R$ Analysis}

The transcription levels of CsARF5, CsDREB3, CsCBF1 and CsCOR were examined using specific primers CsARF5 (qRT)-F/R, CsDREB3 (qRT)-F/R, CsCBF1 (qRT)-F/R and CsCOR (qRT)-F/R, respectively. $\beta$-Actin was used as an internal reference. All of the primers used are shown in Supplemental Table S1. qRT-PCR was carried out simultaneously with three biological replicates and three technical replicates.

\subsection{Detection of EL}

EL was detected according to methods described by Dong et al. (2013) [88]. Leaf discs $(0.2 \mathrm{~g})$ were immersed in $20 \mathrm{~mL}$ deionized water and incubated at $25{ }^{\circ} \mathrm{C}$ for $3 \mathrm{~h}$. The electrical conductivity (EC1) was estimated using a conductivity meter (DDB-303A, Shanghai, China). The leaf discs were boiled for $10 \mathrm{~min}$ and then cooled to detect EC2. EL was calculated according to the following formula: EL=EC1/EC2 × 100 .

\subsection{IAA Content and FMO Activity Assay}

IAA content was measured using high-performance liquid chromatography-triple quadrupole mass spectrometry (Thermo Fisher Scientific, TSQ Quantum Access, San Jose, CA, USA) according to the method of Li et al. (2014) [89], with minor modifications by Zhang et al. (2020) [60]. In brief, leaf samples were extracted with $80 \%$ methanol (containing $30 \mu \mathrm{g} \cdot \mathrm{mL}^{-1}$ sodium diethyldithiocarbamate), and the supernatant was retained by rotary evaporation (Shanghai EYELA, N-1210B, Shanghai, China). Pigment and phenolic impurities of samples were removed using trichloromethane and polyvinylpolypyrrolidone (PVPP), respectively. Auxin was further extracted with ethyl acetate, and then the ester phase was collected. Finally, rotation drying at $36^{\circ} \mathrm{C}$ and drying were dissolved in $1.0 \mathrm{~mL}$ mobile phases (methanol: $0.04 \%$ acetic acid $=45: 55, v / v$ ). The filtrate could then be used directly for HPLC-MS analysis. 
The activity of FMO was detected using an enzyme-linked immunosorbent assay (ELISA) kit (Jiangsu Meimian Industrial Co. Ltd., Yancheng, China) as described by Zhang et al. (2020) [60].

\subsection{Determination of $\mathrm{H}_{2} \mathrm{O}_{2}$ and $\mathrm{O}_{2}{ }^{-}$Contents}

$\mathrm{H}_{2} \mathrm{O}_{2}$ content was estimated with the $\mathrm{H}_{2} \mathrm{O}_{2}$ kit (Nanjing Jiancheng Bioengineering Institute, Nanjing, China) according to the instructions. The $\mathrm{O}_{2}{ }^{-}$- content was detected according to the method of Wang and Luo (1990) [90]. Cellular $\mathrm{H}_{2} \mathrm{O}_{2}$ and $\mathrm{O}_{2}{ }^{-}$- were fluorescently stained with $2^{\prime}, 7^{\prime}$-dichlorodihydrofluorescein diacetate $\left(\mathrm{H}_{2} \mathrm{DCFDA}\right.$, the fluorescent probe of $\mathrm{H}_{2} \mathrm{O}_{2}$ ) (MCE, Cat. No. HY-D0940, Shanghai, China) and dihydroethidium (DHE, $\mathrm{O}_{2}{ }^{-}$- fluorescent probe) (Fluorescence Biotechnology Co. Ltd., Cat. No. 15200, Beijing, China), respectively, as described by Galluzzi and Kroemer (2014) [91] and modified by Zhang et al. (2020) [60]. In brief, the samples were infiltrated in a $20 \mu \mathrm{M} \mathrm{H}_{2} \mathrm{O}_{2}$ fluorescent probe at $25^{\circ} \mathrm{C}$ under dark conditions for $30 \mathrm{~min}$. Then the tissues were rinsed with HEPES$\mathrm{NaOH}$ buffer ( $\mathrm{pH} 7.5$ ). Under excitation at $488 \mathrm{~nm}$ and emission at $522 \mathrm{~nm}$ of an inverted microscope (Leica DMi8), cellular $\mathrm{H}_{2} \mathrm{O}_{2}$ showed obvious green fluorescent coloration. For cellular $\mathrm{O}_{2} \cdot{ }^{-}$measurements, the samples were infiltrated in $10 \mu \mathrm{M}$ DHE at $37^{\circ} \mathrm{C}$ under dark conditions for $30 \mathrm{~min}$. After fixation, the tissues were rinsed with Tris- $\mathrm{HCl}$ buffer ( $\mathrm{pH}$ 7.5). $\mathrm{O}_{2}{ }^{-}$showed strong red fluorescence under excitation at $490 \mathrm{~nm}$ and emission at $520 \mathrm{~nm}$ under an inverted microscope (Leica DMi8).

\subsection{NBT and DAB Staining}

NBT staining of $\mathrm{O}_{2} \cdot{ }^{-}$was performed according to the method of Jabs et al. (1996) [92] with minor modifications. The fresh leaves were washed with distilled water, immersed in $0.5 \mathrm{mM}$ NBT in a vacuum and stained at $28{ }^{\circ} \mathrm{C}$ for $1 \mathrm{~h}$. Then, the leaves were boiled in ethanol:lactic acid:glycerol (3:1:1) mixed solution to remove pigments, and $\mathrm{O}_{2} \cdot{ }^{-}$was visualized in blue-purple coloration. DAB staining of $\mathrm{H}_{2} \mathrm{O}_{2}$ was carried out as described by Thordal-Christensen et al. (1997) [93]. The cleaned fresh leaves were soaked in $1 \mathrm{mM}$ DAB staining solution ( $\mathrm{pH} 3.8$ ) in a vacuum and stained at $28^{\circ} \mathrm{C}$ for $8 \mathrm{~h}$. Then, the leaves were boiled in ethanol:lactic acid:glycerol (3:1:1) mixed solution to remove pigments and $\mathrm{H}_{2} \mathrm{O}_{2}$ was visualized in reddish-brown coloration.

\subsection{EMSAs}

The CsARF5-HIS fusion protein and biotin labeled probes were prepared for EMSAs. The CsARF5-HIS fusion protein was obtained by inducing Escherichia coli BL21 (TransGen Biotech, Beijing, China) with isopropyl $\beta$-D-thiogalactoside (IPTG). The biotin-labeled probes were synthesized by Sangon Biotech (Shanghai, China) Co., Ltd. To perform the EMSAs, the fusion protein was mixed with the probe and incubated at $24{ }^{\circ} \mathrm{C}$ for $30 \mathrm{~min}$. The protein-probe mixture was separated by nondenatured acrylamide gel electrophoresis.

\subsection{Dual Luciferase Assay}

The promoter sequence of CSDREB3 was amplified and cloned into pGreenII 0800-LUC to generate the reporter construct pCsDREB3-LUC. The effector plasmid was constructed by inserting full-length CSARF5 into pGreenII 62-SK. Different plasmid combinations were injected into tobacco (Nicotiana benthamiana) leaves by Agrobacterium tumefaciens LBA4404. The leaves were sprayed with $100 \mathrm{mM}$ luciferin, and luminescence was detected after being placed in darkness for $3 \mathrm{~min}$. Fluorescence images were obtained with a live imaging system (Xenogen, Alameda, California, USA). The fluorescence activity was determined using a fluorescence activity detection kit (Promega, Madison, WI, USA).

\subsection{Statistical Analysis}

All experiments were performed at least in triplicate, and the results are expressed as the mean \pm standard deviation (SD) of three replicates. The data were analyzed statistically 
with DPS software. Duncan's multiple range test was used to compare differences among treatments, and $p<0.05$ was considered statistically significant.

\subsection{Accession Numbers \\ CsARF5 (CsaV3_3G045690), CsDREB3 (CsaV3_2G030880), CsCBF1 (XM_004140746), CsCOR (XM_011659051).}

\section{Conclusions}

$\mathrm{H}_{2} \mathrm{~S}$ treatment increases cold tolerance and auxin content of cucumber. The auxin response factor CsARF5 directly activates the expression of CsDREB3 to improve the cold tolerance of cucumber in response to $\mathrm{H}_{2} \mathrm{~S}$ treatment. This study elucidates the molecular mechanism by which $\mathrm{H}_{2} \mathrm{~S}$ regulates the cold stress response in cucumber by mediating auxin signaling, which will provide insights for further studies on the molecular mechanisms by which $\mathrm{H}_{2} \mathrm{~S}$ regulates cold stress.

Supplementary Materials: The following are available online at https://www.mdpi.com/article/ $10.3390 /$ ijms222413229/s1.

Author Contributions: X.A. and X.Z. designed the experiment; X.Z. performed the research and analyzed the data; X.F., F.L., Y.W. and H.B. worked together with X.Z. to accomplish the experiment X.A. and X.Z. wrote the paper. All authors have read and agreed to the published version of the manuscript.

Funding: This research was funded by The National Science Foundation of China (31572170), The National Key Research and Development Program of China (2018YFD1000800), The Major Science and Technology Innovation of Shandong Province in China (2019JZZY010715) and The Special Fund of Vegetable Industrial Technology System of Shandong Province (SDAIT-05-10).

Institutional Review Board Statement: Not applicable.

Informed Consent Statement: Not applicable.

Data Availability Statement: The data discussed in this publication have been deposited in NCBI's Gene Expression Omnibus along with our lab's previous publication and are accessible through SRA accession: PRJNA579777 (https://www.ncbi.nlm.nih.gov/sra/PRJNA579777, accessed on 26 October 2019).

Conflicts of Interest: All authors agreed with the final manuscript and have no conflicts of interest.

\section{References}

1. Li, L.; Rose, P.; Moore, P.K. Hydrogen sulfide and cell signaling. Annu. Rev. Pharmacol. 2011, 51, 169-187. [CrossRef] [PubMed]

2. Olas, B. Hydrogen sulfide in signaling pathways. Clin. Chim. Acta 2015, 439, 212-218. [CrossRef] [PubMed]

3. Aboubakr, E.M.; Taye, A.; El-Moselhy, M.A.; Hassan, M.K. Protective effect of hydrogen sulfide against cold restraint stressinduced gastric mucosal injury in rats. Arch. Pharm. Res. 2013, 36, 1507-1515. [CrossRef] [PubMed]

4. Zaorska, E.; Tomasova, L.; Koszelewski, D.; Ostaszewski, R.; Ufnal, M. Hydrogen Sulfide in Pharmacotherapy, Beyond the Hydrogen Sulfide-Donors. Biomolecules 2020, 10, 323. [CrossRef]

5. Truong, D.H.; Eghbal, M.A.; Hindmarsh, W.; Roth, S.H.; O’Brien, P.J. Molecular mechanisms of hydrogen sulfide toxicity. Drug Metab. Rev. 2006, 38, 733-744. [CrossRef]

6. Jiang, J.; Chan, A.; Ali, S.; Saha, A.; Haushalter, K.J.; Lam, W.L.M.; Glasheen, M.; Parker, J.; Brenner, M.; Mahon, S.B.; et al. Hydrogen sulfide-mechanisms of toxicity and development of an antidote. Sci. Rep. 2016, 6, 20831. [CrossRef]

7. Li, Z.G.; Min, X.; Zhou, Z.H. Hydrogen sulfide: A signal molecule in plant cross-adaptation. Front. Plant Sci. 2016, 7, 1621. [CrossRef]

8. Hancock, J.T. Hydrogen sulfide and environmental stresses. Environ. Exp. Bot. 2019, 161, 50-56. [CrossRef]

9. Xuan, L.; Li, J.; Wang, X.; Wang, C. Crosstalk between hydrogen sulfide and other signal molecules regulate plant growth and development. Int. J. Mol. Sci. 2020, 21, 4593. [CrossRef]

10. Shi, H.; Ye, T.; Han, N.; Bian, H.; Liu, X.; Chan, Z. Hydrogen sulfide regulates abiotic stress tolerance and biotic stress resistance in Arabidopsis. J. Integr. Plant Biol. 2015, 57, 628-640. [CrossRef] [PubMed]

11. Du, X.; Jin, Z.; Liu, D.; Yang, G.; Pei, Y. Hydrogen sulfide alleviates the cold stress through MPK4 in Arabidopsis thaliana. Plant Physiol. Bioch. 2017, 120, 112-119. [CrossRef] 
12. Zhang, J.; Zhou, M.; Zhou, H.; Zhao, D.; Gotor, C.; Romero, L.C.; Shen, J.; Ge, Z.; Zhang, Z.; Shen, W.; et al. Hydrogen sulfide, a signaling molecule in plant stress responses. J. Integr. Plant Biol. 2021, 63, 146-160. [CrossRef]

13. Fu, P.; Wang, W.; Hou, L.; Liu, X. Hydrogen sulfide is involved in the chilling stress response in Vitis vinifera L. Acta Soc. Bot. Pol. 2013, 82. [CrossRef]

14. Shi, H.; Ye, T.; Chan, Z. Exogenous application of hydrogen sulfide donor sodium hydrosulfide enhanced multiple abiotic stress tolerance in bermudagrass (Cynodon dactylon (L). Pers.). Plant Physiol. Bioch. 2013, 71, 226-234. [CrossRef]

15. Nasibi, F.; Kalantari, K.M.; Tavakoli, Z.M. Effects of Hydrogen Sulfide on Cold-Induced Oxidative Damage in Cucumis sativus L. Int. J. Hortic. Sci. Technol. 2020, 7, 199-211. [CrossRef]

16. Ba, Y.; Zhai, J.; Yan, J.; Li, K.; Xu, H. $\mathrm{H}_{2} \mathrm{~S}$ improves growth of tomato seedlings involving the MAPK signaling. Sci. Hortic. 2021, 288, 110366. [CrossRef]

17. Du, X.; Jin, Z.; Liu, Z.; Liu, D.; Zhang, L.; Ma, X.; Yang, G.; Liu, S.; Guo, Y.; Pei, Y. $\mathrm{H}_{2}$ S Persulfidated and Increased Kinase Activity of MPK4 to Response Cold Stress in Arabidopsis. Front. Mol. Biosci. 2021, 8, 81. [CrossRef]

18. Shibasaki, K.; Uemura, M.; Tsurumi, S.; Rahman, A. Auxin response in Arabidopsis under cold stress: Underlying molecular mechanisms. Plant Cell 2009, 21, 3823-3838. [CrossRef]

19. Rahman, A. Auxin: A regulator of cold stress response. Physiol. Plant. 2013, 147, 28-35. [CrossRef]

20. Zhao, Y. Auxin biosynthesis and its role in plant development. Annu. Rev. Plant Biol. 2010, 61, 49-64. [CrossRef]

21. Lv, B.; Yan, Z.; Tian, H.; Zhang, X.; Ding, Z. Local Auxin Biosynthesis Mediates Plant Growth and Development. Trends Plant Sci. 2019, 24, 6-9. [CrossRef] [PubMed]

22. Dharmasiri, N.; Dharmasiri, S.; Estelle, M. The F-box protein TIR1 is an auxin receptor. Nature 2005, 435, 441-445. [CrossRef]

23. Kepinski, S.; Leyser, O. The Arabidopsis F-box protein TIR1 is an auxin receptor. Nature 2005, 435, 446-451. [CrossRef] [PubMed]

24. Gray, W.M.; Kepinski, S.; Rouse, D.; Leyser, O.; Estelle, M. Auxin regulates SCF TIR1-dependent degradation of AUX/IAA proteins. Nature 2001, 414, 271-276. [CrossRef] [PubMed]

25. Kepinski, S.; Leyser, O. Auxin-induced SCF ${ }^{\text {TIR1 }}$-Aux/IAA interaction involves stable modification of the SCFTIR1 complex. Proc. Natl. Acad. Sci. USA 2004, 101, 12381-12386. [CrossRef] [PubMed]

26. Liscum, E.; Reed, J.W. Genetics of Aux/IAA and ARF action in plant growth and development. Plant Mol. Biol. 2002, 49, 387-400. [CrossRef]

27. Guilfoyle, T.J.; Hagen, G. Auxin response factors. Curr. Opin. Plant Biol. 2007, 10, 453-460. [CrossRef] [PubMed]

28. Weijers, D.; Friml, J. SnapShot: Auxin signaling and transport. Cell 2009, 136, 1172. [CrossRef] [PubMed]

29. Chandler, J.W. Auxin response factors. Plant Cell Environ. 2016, 39, 1014-1028. [CrossRef]

30. Li, S.B.; Xie, Z.Z.; Hu, C.G.; Zhang, J.Z. A review of auxin response factors (ARFs) in plants. Front. Plant Sci. 2016, 7, 47. [CrossRef]

31. Wang, D.; Pei, K.; Fu, Y.; Sun, Z.; Li, S.; Liu, H.; Tang, K.; Han, B.; Tao, Y. Genome-wide analysis of the auxin response factors (ARF) gene family in rice (Oryza sativa $\mathrm{L}$ ). Gene 2007, 394, 13-24. [CrossRef] [PubMed]

32. Shen, C.; Wang, S.; Bai, Y.; Wu, Y.; Zhang, S.; Chen, M.; Guilfoyle, T.J.; Wu, P.; Qi, Y. Functional analysis of the structural domain of ARF proteins in rice (Oryza sativa L.). J. Exp. Bot. 2010, 61, 3971-3981. [CrossRef]

33. Tiwari, S.B.; Hagen, G.; Guilfoyle, T. The roles of auxin response factor domains in auxin-responsive transcription. Plant Cell 2003, 15, 533-543. [CrossRef] [PubMed]

34. Ulmasov, T.; Hagen, G.; Guilfoyle, T.J. Dimerization and DNA binding of auxin response factors. Plant J. 1999, 19, 309-319. [CrossRef] [PubMed]

35. Kim, J.; Harter, K.; Theologis, A. Protein-protein interactions among the Aux/IAA proteins. Proc. Natl. Acad. Sci. USA 1997, 94 , 11786-11791. [CrossRef]

36. Piya, S.; Shrestha, S.K.; Binder, B.; Stewart, C.N.; Hewezi, T. Protein-protein interaction and gene co-expression maps of ARFs and Aux/IAAs in Arabidopsis. Front. Plant Sci. 2014, 5, 744. [CrossRef]

37. Mallory, A.C.; Bartel, D.P.; Bartel, B. MicroRNA-directed regulation of Arabidopsis auxin response factor17 is essential for proper development and modulates expression of early auxin response genes. Plant Cell 2005, 17, 1360-1375. [CrossRef]

38. Okushima, Y.; Overvoorde, P.J.; Arima, K.; Alonso, J.M.; Chan, A.; Chang, C.; Ecker, J.R.; Hughes, B.; Lui, A.; Nguyen, D.; et al. Function genomic analysis of the auxin response factor gene family members in Arabidopsis thaliana: Unique and overlapping functions of ARF7 and ARF19. Plant Cell 2005, 17, 444-463. [CrossRef] [PubMed]

39. Fukaki, H.; Tasaka, M. Hormone interactions during lateral root formation. Plant Mol. Biol. 2009, 69, 437-449. [CrossRef]

40. Orosa-Puente, B.; Leftley, N.; Wangenheim, D.V.; Banda, J.; Srivastava, A.K.; Hill, K.; Truskina, J.; Bhosale, R.; Morris, E.; Srivastava, M.; et al. Root branching toward water involves posttranslational modification of transcription factor ARF7. Science 2018, 362, 1407-1410. [CrossRef]

41. Lee, H.W.; Cho, C.; Pandey, S.K.; Park, Y.; Kim, M.J.; Kim, J. LBD16 and LBD18 acting downstream of ARF7 and ARF19 are involved in adventitious root formation in Arabidopsis. BMC Plant Biol. 2019, 19, 46. [CrossRef]

42. Liu, K.; Li, Y.; Chen, X.; Li, L.; Liu, K.; Zhao, H.; Wang, Y.; Han, S. ERF72 interacts with ARF6 and BZR1 to regulate hypocotyl elongation in Arabidopsis. J. Exp. Bot. 2018, 69, 3933-3947. [CrossRef] [PubMed]

43. Reed, J.W.; Wu, M.F.; Reeves, P.H.; Hodgens, C.; Yadav, V.; Hayes, S.; Pierik, R. Three Auxin Response Factors Promote Hypocotyl Elongation. Plant Physiol. 2018, 178, 864-875. [CrossRef] 
44. Wang, X.; Yu, R.; Wang, J.; Lin, Z.; Han, X.; Deng, Z.; Fan, L.; He, H.; Deng, X.W.; Chen, H. The Asymmetric Expression of SAUR Genes Mediated by ARF7/19 Promotes the Gravitropism and Phototropism of Plant Hypocotyls. Cell Rep. 2020, 31, 107529. [CrossRef]

45. Zhang, M.M.; Zhang, H.K.; Zhai, J.F.; Zhang, X.S.; Sang, Y.L.; Cheng, Z.J. ARF4 regulates shoot regeneration through coordination with ARF5 and IAA12. Plant Cell Rep. 2021, 40, 315-325. [CrossRef]

46. Nagpal, P.; Ellis, C.M.; Weber, H.; Ploense, S.E.; Barkawi, L.S.; Guilfoyle, T.J.; Hagen, G.; Alonso, J.M.; Cohen, J.D.; Farmer, E.E.; et al. Auxin response factors ARF6 and ARF8 promote jasmonic acid production and flower maturation. Development 2005, 132, 4107-4118. [CrossRef]

47. Finet, C.; Fourquin, C.; Vinauger, M.; Berne-Dedieu, A.; Chambrier, P.; Paindavoine, S.; Scutt, C.P. Parallel structural evolution of auxin response factors in the angiosperms. Plant J. 2010, 63, 952-959. [CrossRef]

48. Ellis, C.M.; Nagpal, P.; Young, J.C.; Hage, G.; Guilfoyle, T.J.; Reed, J.W. AUXIN RESPONSE FACTOR1 and AUXIN RESPONSE FACTOR2 regulate senescence and floral organ abscission in Arabidopsis thaliana. Development 2005, 132, 4563-4574. [CrossRef] [PubMed]

49. Inukai, Y.; Sakamoto, T.; Ueguchi-Tanaka, M.; Shibata, Y.; Gomi, K.; Umemura, I.; Matsuoka, M. Crown rootless1, which is essential for crown root formation in rice, is a target of an AUXIN RESPONSE FACTOR in auxin signaling. Plant Cell 2005, 17, 1387-1396. [CrossRef] [PubMed]

50. Attia, K.A.; Abdelkhalik, A.F.; Ammar, M.H.; Wei, C.; Yang, J.; Lightfoot, D.A.; El-Shemy, H.A. Antisense phenotypes reveal a functional expression of OsARF1, an auxin response factor, in transgenic rice. Curr. Issues Mol. Biol. 2009, 11, I29-I34. [CrossRef]

51. Qi, Y.; Wang, S.; Shen, C.; Zhang, S.; Chen, Y.; Xu, Y.; Jiang, D. OsARF12, a transcription activator on auxin response gene, regulates root elongation and affects iron accumulation in rice (Oryza sativa). New Phytol. 2012, 193, 109-120. [CrossRef] [PubMed]

52. Wang, S.; Zhang, S.; Sun, C.; Xu, Y.; Chen, Y.; Yu, C.; Qian, Q.; Jiang, D.; Qi, Y. Auxin response factor (OsARF12), a novel regulator for phosphate homeostasis in rice (Oryza sativa L.). New Phytol. 2014, 201, 91-103. [CrossRef]

53. Shen, C.; Wang, S.; Zhang, S.; Xu, Y.; Qian, Q.; Qi, Y.; Jiang, D.A. OsARF16, a transcription factor, is required for auxin and phosphate starvation response in rice (Oryza sativa L.). Plant Cell Environ. 2013, 36, 607-620. [CrossRef]

54. Shen, C.; Yue, R.; Yang, Y.; Zhang, L.; Sun, T.; Tie, S.; Wang, H. OsARF16 is involved in cytokinin-mediated inhibition of phosphate transport and phosphate signaling in rice (Oryza sativa L.). PLoS ONE 2014, 9, e112906. [CrossRef]

55. Shen, C.; Yue, R.; Sun, T.; Zhang, L.; Yang, Y.; Wang, H. OsARF16, a transcription factor regulating auxin redistribution, is required for iron deficiency response in rice (Oryza sativa L.). Plant Sci. 2015, 231, 148-158. [CrossRef]

56. Zhang, S.; Wang, S.; Xu, Y.; Yu, C.; Shen, C.; Qian, Q.; Qi, Y. The auxin response factor, OsARF19, controls rice leaf angles through positively regulating OsGH3-5 and OsBRI1. Plant Cell Environ. 2015, 38, 638-654. [CrossRef]

57. Qin, Q.; Li, G.; Jin, L.; Huang, Y.; Wang, Y.; Wei, C.; Xu, Z.; Yang, Z.; Wang, H.; Li, Y. Auxin response factors (ARFs) differentially regulate rice antiviral immune response against rice dwarf virus. PLoS Pathog. 2020, 16, e1009118. [CrossRef]

58. Zhang, H.; Li, L.; He, Y.; Qin, Q.; Chen, C.; Wei, Z.; Tan, X.; Xie, K.; Zhang, R.; Hong, G.; et al. Distinct modes of manipulation of rice auxin response factor OsARF17 by different plant RNA viruses for infection. Proc. Natl. Acad. Sci. USA 2020, 117, $9112-9121$. [CrossRef]

59. Qiao, J.; Jiang, H.; Lin, Y.; Shang, L.; Wang, M.; Li, D.; Fu, X.; Geisler, M.; Qi, Y.; Gao, Z.; et al. A Novel miR167a-OsARF6-OsAUX3 Module Regulates Grain Length and Weight in Rice. Mol. Plant 2021, 14, 1683-1698. [CrossRef]

60. Zhang, X.W.; Liu, F.J.; Zhai, J.; Li, F.D.; Bi, H.G.; Ai, X.Z. Auxin acts as a downstream signaling molecule involved in hydrogen sulfide-induced chilling tolerance in cucumber. Planta 2020, 251, 1-19. [CrossRef] [PubMed]

61. Zhou, M.L.; Ma, J.T.; Pang, J.F.; Zhang, Z.L.; Tang, Y.X.; Wu, Y.M. Regulation of plant stress response by dehydration responsive element binding (DREB) transcription factors. Afr. J. Biotechnol. 2010, 9, 9255-9269. [CrossRef]

62. Lata, C.; Prasad, M. Role of DREBs in regulation of abiotic stress responses in plants. J. Exp. Bot. 2011, 62, 4731-4748. [CrossRef] [PubMed]

63. Huang, D.; Huo, J.; Liao, W. Hydrogen sulfide: Roles in plant abiotic stress response and crosstalk with other signals. Plant Sci. 2021, 302, 110733. [CrossRef]

64. Guo, H.M.; Xiao, T.Y.; Zhou, H.; Xie, Y.J.; Shen, W.B. Hydrogen sulfide: A versatile regulator of environmental stress in plants. Acta Physiol. Plant. 2016, 38, 16. [CrossRef]

65. Li, Z.G.; Xiang, R.H.; Wang, J.Q. Hydrogen sulfide-phytohormone interaction in plants under physiological and stress conditions. J. Plant Growth Regul. 2021, 40, 2476-2484. [CrossRef]

66. Jin, Z.P.; Xue, S.W.; Luo, Y.A.; Tian, B.H.; Fang, H.H.; Li, H.; Pei, Y.X. Hydrogen sulfide interacting with abscisic acid in stomatal regulation responses to drought stress in Arabidopsis. Plant Physiol. Biochem. 2013, 62, 41-46. [CrossRef]

67. Hou, Z.H.; Wang, L.X.; Liu, J.; Hou, L.X.; Liu, X. Hydrogen sulfide regulates ethylene-induced stomatal closure in Arabidopsis thaliana. J. Integr. Plant Biol. 2013, 55, 277-289. [CrossRef] [PubMed]

68. Li, Z.G.; Xie, L.R.; Li, X.J. Hydrogen sulfide acts as a downstream signal molecule in salicylic acid-induced heat tolerance in maize (Zea mays L.) seedlings. J. Plant Physiol. 2015, 177, 121-127. [CrossRef]

69. Qiao, Z.J.; Jing, T.; Liu, Z.Q.; Zhang, L.P.; Jin, Z.P.; Liu, D.M.; Pei, Y.X. $\mathrm{H}_{2} \mathrm{~S}$ acting as a downstream signaling molecule of SA regulates Cd tolerance in Arabidopsis. Plant Soil 2015, 393, 137-146. [CrossRef]

70. Hou, Z.; Liu, J.; Hou, L.; Li, X.; Liu, X. $\mathrm{H}_{2} \mathrm{~S}$ may function downstream of $\mathrm{H}_{2} \mathrm{O}_{2}$ in jasmonic acid-induced stomatal closure in Vicia faba. Chin. Bull. Bot. 2011, 46, 396-406. [CrossRef] 
71. Miura, K.; Tada, Y. Regulation of water, salinity, and cold stress responses by salicylic acid. Front. Plant Sci. 2014, 5, 4. [CrossRef]

72. Kazan, K. Diverse roles of jasmonates and ethylene in abiotic stress tolerance. Trends Plant Sci. 2015, 20, 219-229. [CrossRef]

73. Hu, Y.; Jiang, Y.; Han, X.; Wang, H.; Pan, J.; Yu, D. Jasmonate regulates leaf senescence and tolerance to cold stress: Crosstalk with other phytohormones. J. Exp. Bot. 2017, 68, 1361-1369. [CrossRef]

74. Zhao, Y. Essential Roles of Local Auxin Biosynthesis in Plant Development and in Adaptation to Environmental Changes. Annu. Rev. Plant Biol. 2018, 69, 417-435. [CrossRef]

75. Blakeslee, J.J.; Rossi, T.S.; Kriechbaumer, V. Auxin biosynthesis: Spatial regulation and adaptation to stress. J. Exp. Bot. 2019, 70, 5041-5049. [CrossRef]

76. Popko, J.; Hänsch, R.; Mendel, R.R.; Polle, A.; Teichmann, T. The role of abscisic acid and auxin in the response of poplar to abiotic stress. Plant Biol. 2010, 12, 242-258. [CrossRef] [PubMed]

77. Du, H.; Liu, H.; Xiong, L. Endogenous auxin and jasmonic acid levels are differentially modulated by abiotic stresses in rice. Front. Plant Sci. 2013, 4, 397. [CrossRef]

78. Aslam, M.; Sugita, K.; Qin, Y.; Rahman, A. Aux/IAA14 Regulates microRNA-Mediated Cold Stress Response in Arabidopsis Roots. Int. J. Mol. Sci. 2020, 21, 8441. [CrossRef] [PubMed]

79. Kalluri, U.C.; DiFazio, S.P.; Brunner, A.M.; Tuskan, G.A. Genome-wide analysis of Aux/IAA and ARF gene families in Populus trichocarpa. BMC Plant Biol. 2007, 7, 1-14. [CrossRef]

80. He, X.J.; Mu, R.L.; Cao, W.H.; Zhang, Z.G.; Zhang, J.S.; Chen, S.Y. AtNAC2, a transcription factor downstream of ethylene and auxin signaling pathways, is involved in salt stress response and lateral root development. Plant J. 2005, 44, 903-916. [CrossRef]

81. Liu, Q.; Kasuga, M.; Sakuma, Y.; Abe, H.; Miura, S.; Yamaguchi-Shinozaki, K.; Shinozaki, K. Two transcription factors, DREB1 and DREB2, with an EREBP/AP2 DNA binding domain separate two cellular signal transduction pathways in drought-and low-temperature-responsive gene expression, respectively, in Arabidopsis. Plant Cell 1998, 10, 1391-1406. [CrossRef] [PubMed]

82. Gilmour, S.J.; Zarka, D.G.; Stockinger, E.J.; Salazar, M.P.; Houghton, J.M.; Thomashow, M.F. Low temperature regulation of the Arabidopsis CBF family of AP2 transcriptional activators as an early step in cold-induced COR gene expression. Plant J. 1998, 16, 433-442. [CrossRef]

83. Lee, S.J.; Kang, J.Y.; Park, H.J.; Kim, M.D.; Bae, M.S.; Choi, H.I.; Kim, S.Y. DREB2C interacts with ABF2, a bZIP protein regulating abscisic acid-responsive gene expression, and its overexpression affects abscisic acid sensitivity. Plant Physiol. 2010, 153, 716-727. [CrossRef]

84. Chen, J.Q.; Dong, Y.; Wang, Y.J.; Liu, Q.; Zhang, J.S.; Chen, S.Y. An AP2/EREBP-type transcription-factor gene from rice is cold-inducible and encodes a nuclear-localized protein. Theor. Appl. Genet. 2003, 107, 972-979. [CrossRef] [PubMed]

85. Dubouzet, J.G.; Sakuma, Y.; Ito, Y.; Kasuga, M.; Dubouzet, E.G.; Miura, S.; Seki, M.; Shinozaki, K.; Yamaguchi-Shinozaki, K. OsDREB genes in rice, Oryza sativa L., encode transcription activators that function in drought-, high-salt-and cold-responsive gene expression. Plant J. 2003, 33, 751-763. [CrossRef]

86. Wang, Q.; Guan, Y.; Wu, Y.; Chen, H.; Chen, F.; Chu, C. Overexpression of a rice OsDREB1F gene increases salt, drought, and low temperature tolerance in both Arabidopsis and rice. Plant Mol. Biol. 2008, 67, 589-602. [CrossRef]

87. Matsukura, S.; Mizoi, J.; Yoshida, T.; Todaka, D.; Ito, Y.; Maruyama, K.; Shinozaki, K.; Yamaguchi-Shinozaki, K. Comprehensive analysis of rice DREB2-type genes that encode transcription factors involved in the expression of abiotic stress-responsive genes. Mol. Genet. Genomics 2010, 283, 185-196. [CrossRef]

88. Dong, X.B.; Bi, H.G.; Wu, G.X.; Ai, X.Z. Drought-induced chilling tolerance in cucumber involves membrane stabilisation improved by antioxidant system. Int. J. Plant. Prod. 2013, 7, 67-80.

89. Li, Y.; Xu, J.; Zheng, L.; Li, M.; Yan, X.; Luo, Q. Simultaneous determination of ten phytohormones in five parts of Sargasumfusiforme (Hary.) Seichell by high performance liquid chromatography-triple quadrupole mass spectrometry. Chin. J. Chromatogr. 2014, 32, 861-866. [CrossRef]

90. Wang, A.G.; Luo, G.H. Quantitative relation between the reaction of hydroxylamine and superoxide anion radicals in plants. Plant Physiol. Commun. 1990, 26, 55-57. [CrossRef]

91. Galluzzi, L.; Kroemer, G. Conceptual Background and Bioenergetic/Mitochondrial Aspects of Oncometabolism; Elsevier: Amsterdam, The Netherlands, 2014; p. 542.

92. Jabs, T.; Dietrich, R.A.; Dangl, J.L. Initiation of runaway cell death in an Arabidopsis mutant by extracellular superoxide. Science 1996, 27, 1853-1856. [CrossRef]

93. Thordal-Christensen, H.; Zhang, Z.; Wei, Y.; Collinge, D.B. Subcellular localization of $\mathrm{H}_{2} \mathrm{O}_{2}$ in plants: $\mathrm{H}_{2} \mathrm{O}_{2}$ accumulation in papillae and hypersensitive response during the barley-powdery mildew interaction. Plant J. 1997, 11, 1187-1194. [CrossRef] 